\title{
¿Seasonality and Trends of Drivers of Mesoscale Convective Systems in Southern West Africa
}

\author{
Cornelia Klein, ${ }^{\mathrm{a}, \mathrm{b}}$ Francis Nkrumah, ${ }^{\mathrm{c}}$ Christopher M. TAylor,${ }^{\mathrm{a}, \mathrm{d}}$ AND EliJAh A. Adefisan ${ }^{\mathrm{e}}$ \\ ${ }^{\mathrm{a}}$ U.K. Centre for Ecology and Hydrology, Wallingford, United Kingdom \\ ${ }^{\mathrm{b}}$ Department of Atmospheric and Cryospheric Sciences, University of Innsbruck, Innsbruck, Austria \\ ${ }^{\mathrm{c}}$ University of Cape Coast, Cape Coast, Ghana \\ ${ }^{\mathrm{d}}$ National Centre for Earth Observation, Wallingford, United Kingdom \\ ${ }^{\mathrm{e}}$ The Federal University of Technology, Akure, Nigeria
}

(Manuscript received 18 March 2020, in final form 10 September 2020)

\begin{abstract}
Mesoscale convective systems (MCSs) are the major source of extreme rainfall over land in the tropics and are expected to intensify with global warming. In the Sahel, changes in surface temperature gradients and associated changes in wind shear have been found to be important for MCS intensification in recent decades. Here we extend that analysis to southern West Africa (SWA) by combining 34 years of cloud-top temperatures with rainfall and reanalysis data. We identify clear trends in intense MCSs since 1983 and their associated atmospheric drivers. We also find a marked annual cycle in the drivers, linked to changes in the convective regime during the progression of the West African monsoon. Before the peak of the first rainy season, we identify a shear regime where increased temperature gradients play a crucial role for MCS intensity trends. From June onward, SWA moves into a less unstable, moist regime during which MCS trends are mainly linked to frequency increase and may be more influenced by total column water vapor. However, during both seasons we find that MCSs with the most intense convection occur in an environment with stronger wind shear, increased low-level humidity, and drier midlevels. Comparing the sensitivity of MCS intensity and peak rainfall to low-level moisture and wind shear conditions preceding events, we find a dominant role for wind shear. We conclude that MCS trends are directly linked to a strengthening of two distinct convective regimes that cause the seasonal change of SWA MCS characteristics. However, the convective environment that ultimately produces the most intense MCSs remains the same.
\end{abstract}

KEYWORDS: Convective storms; Seasonal variability; Trends

\section{Introduction}

Global mean surface temperatures have been increasing at an average rate of $0.15^{\circ}-0.20^{\circ} \mathrm{C}$ per decade since the late $1970 \mathrm{~s}$, most of which has been attributed to anthropogenic emissions of greenhouse gases (Hansen et al. 2010; IPCC 2014). As the atmospheric precipitable water capacity increases at a fixed rate with rising temperatures, an increase in extreme precipitation at a rate in line with the Clausius-Clapeyron scaling of $7 \% \mathrm{~K}^{-1}$ has been suggested and in many cases confirmed from rain gauges (Hardwick Jones et al. 2010; Panthou et al. 2014) and model simulations (Allen and Ingram 2002; Pall et al. 2007; Singleton and Toumi 2013). However, several studies highlight dynamical processes as an important factor for the disproportionate intensification of convective rainfall beyond Clausius-Clapeyron scaling, although the contribution remains highly dependent on respective regions and seasons (Westra et al. 2014; Emori and Brown 2005; Nie et al. 2018; Liu et al. 2009; Lenderink et al. 2017).

For the Sahel in West Africa, Taylor et al. (2017, hereafter T17) found a tripling of the most intense mesoscale convective systems (MCSs) since the 1980s, which they attribute to a dynamical intensification of MCSs driven by a strengthening of the temperature gradient between the warming Sahara and the wetter southern regions of West Africa. This temperature

๖ Denotes content that is immediately available upon publication as open access.

Corresponding author: Cornelia Klein, cornkle@ceh.ac.uk gradient is increasing due to differences in surface moisture availability. In deserts and semiarid regions, even a small rise of water vapor content in the dry atmosphere signifies a considerable increase in the longwave downward radiation and therefore surface heating, which cannot be buffered by evaporative cooling (Wei et al. 2017). This makes dry ecosystems particularly sensitive to changes in the surface energy budget. They exhibit an amplified warming (Ji et al. 2014), which reaches 2-4 times that of the tropical-mean temperature trend from 1997 to 2012 in the case of the Sahara (Cook and Vizy 2015). Associated changes in temperature gradients may then affect regional atmospheric circulations, baroclinicity, and low-level wind shear. The latter is known to foster the organization of MCSs and, in many cases, was found to be an important ingredient for the development of intense and extreme MCSs (Omotosho 1990; Corfidi 2003; Coniglio et al. 2010; Nicholls and Mohr 2010).

The processes by which wind shear ultimately affects the intensity of MCSs is still a point of discussion. Alfaro and Khairoutdinov (2015) highlighted the importance of wind shear in increasing the inflow of convectively unstable air into storms, which strongly affects their mesoscale dynamics and intensity.

Publisher's Note: This article was revised on 25 November 2020 to fix the affiliations of coauthor Taylor that were incorrectly identified when originally published.

This article is licensed under a Creative Commons Attribution 4.0 license (http://creativecommons.org/ licenses/by/4.0/).

DOI: 10.1175/JCLI-D-20-0194.1 


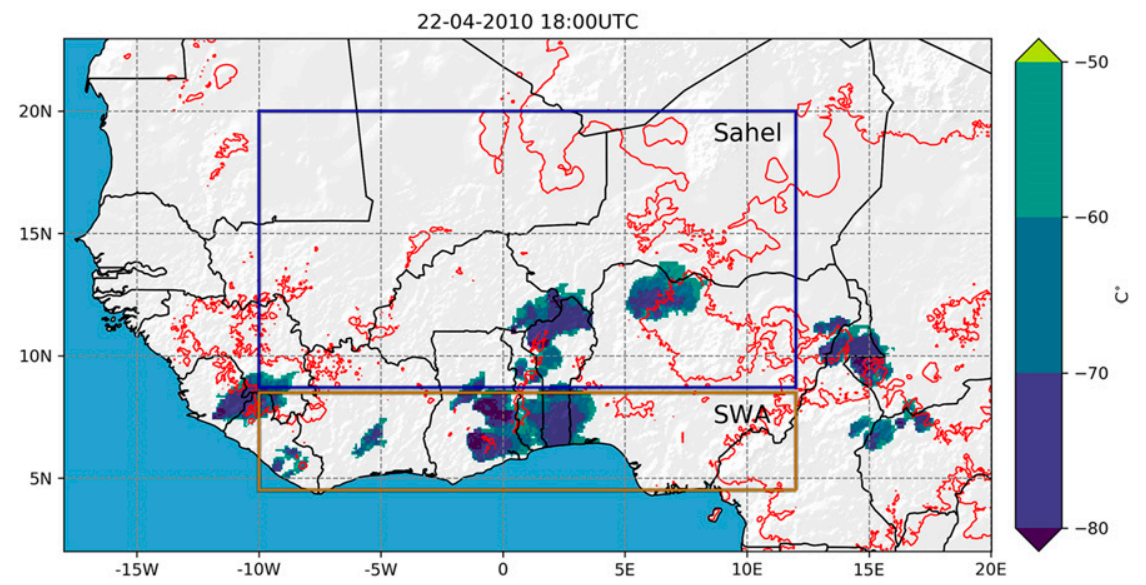

FIG. 1. Cloud-top temperatures of MCSs with an area threshold larger than $5000 \mathrm{~km}^{2}$ and temperatures below $-50^{\circ} \mathrm{C}$ (shading). Dark blue areas indicate the subset of intense MCSs below $-70^{\circ} \mathrm{C}$. Boxes depict the main study region of southern West Africa (SWA; orange box; $10^{\circ} \mathrm{W}-12^{\circ} \mathrm{E}, 4.5^{\circ}-8.5^{\circ} \mathrm{N}$ ) and the Sahel region (blue box; $10^{\circ} \mathrm{W}-12^{\circ} \mathrm{E}, 9^{\circ}-20^{\circ} \mathrm{N}$ ). Red contours indicate topography above $450 \mathrm{~m}$.

Reinforced circulations result in more moisture from unstable atmospheric layers being lifted into MCSs, fueling wider and more vigorous updrafts by the release of latent heat (Alfaro 2017). Trenberth et al. (2003) hypothesized that the intensity increase is linked to a larger area functioning as moisture source when convergence increases. Based on an idealized cloud model, Peters et al. (2019) found that wind shear supports wider updrafts that are less susceptible to losing buoyancy via entrainment. Looking at cloud-cloud interactions in idealized simulations, Moseley et al. (2016) found that more organized storms exhibit intensified moisture convergence at the storm front linked to more rapid scale growth under wind shear conditions. They state that the generation of intense convergence is the mechanism that drives the observed scale growth in storm circulations, and thereby precipitation event size and intensity. In line with that, T17 illustrated from GPS observations that MCS intensity was correlated with the increase in moisture content in the atmosphere over about $6 \mathrm{~h}$ before the arrival of the MCS front. However, it should be noted that wind shear is only one contributing factor for enhanced MCS updraft strength. A complex interplay of elements of the West African monsoon system that help to increase convective available potential energy (CAPE), such as the position of the intertropical discontinuity, moisture advection with the monsoon flow (Vizy and Cook 2018), African easterly wave phase (Fink et al. 2006), and land surface conditions (Klein and Taylor 2020), ultimately creates favorable conditions for particularly intense convection.

Generally, regions potentially affected by the intensification of temperature gradients and hence strengthened baroclinic zones are not static but will vary on both interannual and climatological time scales. For example, Taylor et al. (2018) likewise found a relationship between strong warming events in the southeastern Sahara and more intense MCSs to the south in the Congo Basin at the start of the rainy season. This confirms that the effect of temperature gradient intensification is not necessarily confined to semiarid regions. It may similarly apply to tropical climates that border regions with water limitation during transitional periods.

In this study, we focus on southern West Africa (SWA; Fig. $\left.1,10^{\circ} \mathrm{W}-12^{\circ} \mathrm{E}, 4.5^{\circ}-8.5^{\circ} \mathrm{N}\right)$, which exhibits a humid to subhumid climate. The region is characterized by a bimodal rainfall distribution featuring two distinct rainy seasons (Nicholson 2018). This is related to the inland progression of the tropical rain belt during April-June ("first rainy season") and its equatorward retreat between September and November ("second rainy season") (Thorncroft et al. 2011). The first rainy season marks the wetting-up of soils after the dry season, and a transition to a latent heat-dominated surface energy balance. This is in contrast to the still-dry Sahel to the north, thus creating a strong temperature gradient between SWA and the Sahel. A favorably sheared environment for MCS development is given by the presence of the African easterly jet (AEJ) at midlevels $(600-700 \mathrm{hPa}$ - a thermal wind that shifts in position with strongest meridional temperature gradients. Even though MCSs contribute a considerable amount of total rainfall (Nesbitt et al.2006) and are the major factor for rainfall extremes in SWA (Omotosho 1985), relatively little is known about their drivers or potential MCS trends in this region.

Maranan et al. (2018) conducted an extensive study on different rainfall types in SWA, and attributed $56 \%-71 \%$ of total rainfall to MCSs. According to them, typical preconvective conditions that favor MCS development over more localized rainfall include high CAPE, high convective inhibition, and dry midlevels that allow higher potential downdraft acceleration. Furthermore, increased moisture convergence and wind shear are commonly associated with more intense MCSs. In particular, they note that wind shear strength is the most potent predictor for the horizontal extent and, therefore, for the level of organization of MCSs. However, it is still unclear whether this convective environment is representative for MCS development over the entire seasonal cycle, and whether different drivers might have contributed to historical MCS changes. 
Trend studies for SWA have so far focused directly on rainfall from rain gauges (Sanogo et al. 2015; Nkrumah et al. 2019) and satellite retrievals (Bichet and Diedhiou 2018). They agree on a significant trend in indicators for extreme rainfall but find no clear signal for rainfall totals.

Here, we focus on large-scale MCS trends across SWA, as identified from thermal infared imagery. This can help to understand the extent to which extreme rainfall trends identified in the studies above are related to changes in MCS characteristics. We identify distinct regimes controlling the nature of convection at different times of year, and interpret observed MCS trends in terms of a strengthening of these regimes. We furthermore evaluate typical prestorm convective environments, allowing us to compare the importance of dynamic versus thermodynamics controls on convective intensity. Data and methods are described in the next section, followed by an examination of interannual variability and trends in MCSs and their drivers. This includes consideration of how changing MCS properties affect daily and seasonal rainfall trends. Section 4 describes the seasonality of key atmospheric and MCS properties, relating these to different convective regimes. Our analysis concludes with consideration of MCS drivers at the event time scale.

\section{Data and methods}

For thunderstorms over land in the tropics and subtropics, cloud-top temperatures are a useful proxy for updraft velocities and hence convective intensity (Cecil et al. 2005; Zipser et al. 2006). However, while convective intensity is likely to be associated with some forms of extreme weather, this does not necessarily include precipitation intensity. For Sahelian MCSs, studies tend to suggest a clear relationship between minimum cloud-top temperatures and instantaneous rainfall intensities (e.g., Goyens et al. 2012; Klein et al. 2018), while studies that include the moister SWA region highlight discrepancies (Hamada et al. 2015). At the same time, derived trends direct from available rainfall products show large uncertainties over West Africa (Maidment et al. 2015). We therefore focus on convective intensity and consider trends in cloud-top temperatures only, but provide information on the seasonal relationship of cloud-top temperatures and rainfall.

Following many previous West African studies (Toledo Machado et al. 1992; Arnaud et al. 1992; Laing et al. 1999; Mathon et al. 2002), we identify individual MCSs using thermal-infrared imagery on board the Meteosat series of geostationary satellites. Meteosat satellites (first and second generation) provide subhourly records of cloud-top temperatures, covering a climatological time period going back to 1982 . They provide a full image of the African continent at least every $30 \mathrm{~min}$ at a spatial resolution of $\sim 3-5 \mathrm{~km}$. Those data are the basis for GRIDSAT-B1, a reprocessed Climate Data Record version available every $3 \mathrm{~h}$ at a resolution of $0.07^{\circ}$ (www.ncdc.noaa.gov/gridsat). GRIDSAT-B1 is cross-calibrated and corrected for effects of sensor changes between different Meteosat satellites with the aim to create a homogenized dataset that is suitable for climate variability and trend analyses, with an estimated calibration uncertainty of less than $0.1^{\circ} \mathrm{C}$ per decade
(Knapp et al. 2011). GRIDSAT-B1 has been evaluated and applied in previous MCS trend studies over Africa (e.g., T17; Taylor et al. 2018).

We define an MCS as a contiguous cold cloud structure larger than $5000 \mathrm{~km}^{2}$ (a diameter of $\sim 80 \mathrm{~km}$ for an idealized circular MCS; Mathon et al. 2002; Fink et al. 2006). We use two different temperature thresholds, defining all $\left(-50^{\circ} \mathrm{C}\right.$ threshold) and cold ( $-70^{\circ} \mathrm{C}$ threshold) MCSs. The cold MCSs are by definition a subsample of the "all" MCS sample and define storms with particularly wide convective cores (i.e., MCSs with a high degree of convective organization). The group of cold MCSs can also be expected to be characterized by on average more intense convection. The $-70^{\circ} \mathrm{C}$ threshold corresponds to a minimum vertical extent of approximately $14 \mathrm{~km}$ based on collocated temperature lapse rates from the ERA5 reanalysis dataset (CDS 2017). While the cold MCSs can be expected to be characterized by on average more intense convection than the "all" MCS sample, they do not exclusively reflect MCS intensity extremes.

Cold MCS cloud cover (\%) is computed at the $0.5^{\circ}$ scale based on the fractional area containing contiguous pixels below $-70^{\circ} \mathrm{C}$ and larger than $5000 \mathrm{~km}^{2}$, while MCS frequency $\left(\right.$ day $\left.^{-1}\right)$ is computed from the average number of discrete MCSs centered within the SWA study region (orange box in Fig. $\left.1 ; 10^{\circ} \mathrm{W}-12^{\circ} \mathrm{E}, 4.5^{\circ}-8.5^{\circ} \mathrm{N}\right)$. Finally, MCS temperature is defined as the mean temperature of pixels within a $-50^{\circ} \mathrm{C}$ MCS, and is considered a measure of convective intensity.

We perform MCS trend analyses using the GRIDSAT-B1 data for the period 1983-2017. Trends in atmospheric variables such as wind shear, humidity, and temperature gradients are derived from monthly average 1200 UTC (equal to local time) conditions from ERA5 for the GRIDSAT period since 1983. At 1200 UTC, convective activity is at a minimum, providing a sample that is more representative of preconvective atmospheric conditions. All trends are identified based on a MannKendall test and we compute correlations on detrended time series to isolate interannual variability. We note that trends in reanalysis need to be treated with some caution in observationsparse areas (Cook and Vizy 2015). In general, trends in humidity are less well constrained than for temperature or wind, and can be strongly affected by changes in assimilated observations (Lorenz and Kunstmann 2012; Allan et al. 2014). This uncertainty provides an important caveat, particularly when considering the role of moisture as a driver in MCS trends. Therefore, ERA5 trend patterns in moisture-related variables were compared to trends in the MERRA-2 reanalysis over the same time period $\left(0.5^{\circ}\right.$, Gelaro et al. 2017), and are briefly discussed but not shown in the results.

In a ddition to interannual trends and variability, we perform event-based analyses that link synchronous snapshots of cloud-top temperature and rainfall with pre-event atmospheric conditions. For this we use the original Meteosat Second Generation (MSG) cloud-top temperature data, which are available every $15 \mathrm{~min}$ from the Eumetsat archive (Schmetz et al. 2002; https://navigator. eumetsat.int/product/EO:EUM:DAT:MSG:HRSEVIRI). Rainfall snapshots are taken from the "high-quality precipitation" (HQ) field within the Integrated Multi-satellite Retrievals for Global Precipitation Measurement (IMERG; Huffman et al. 2019) dataset. 

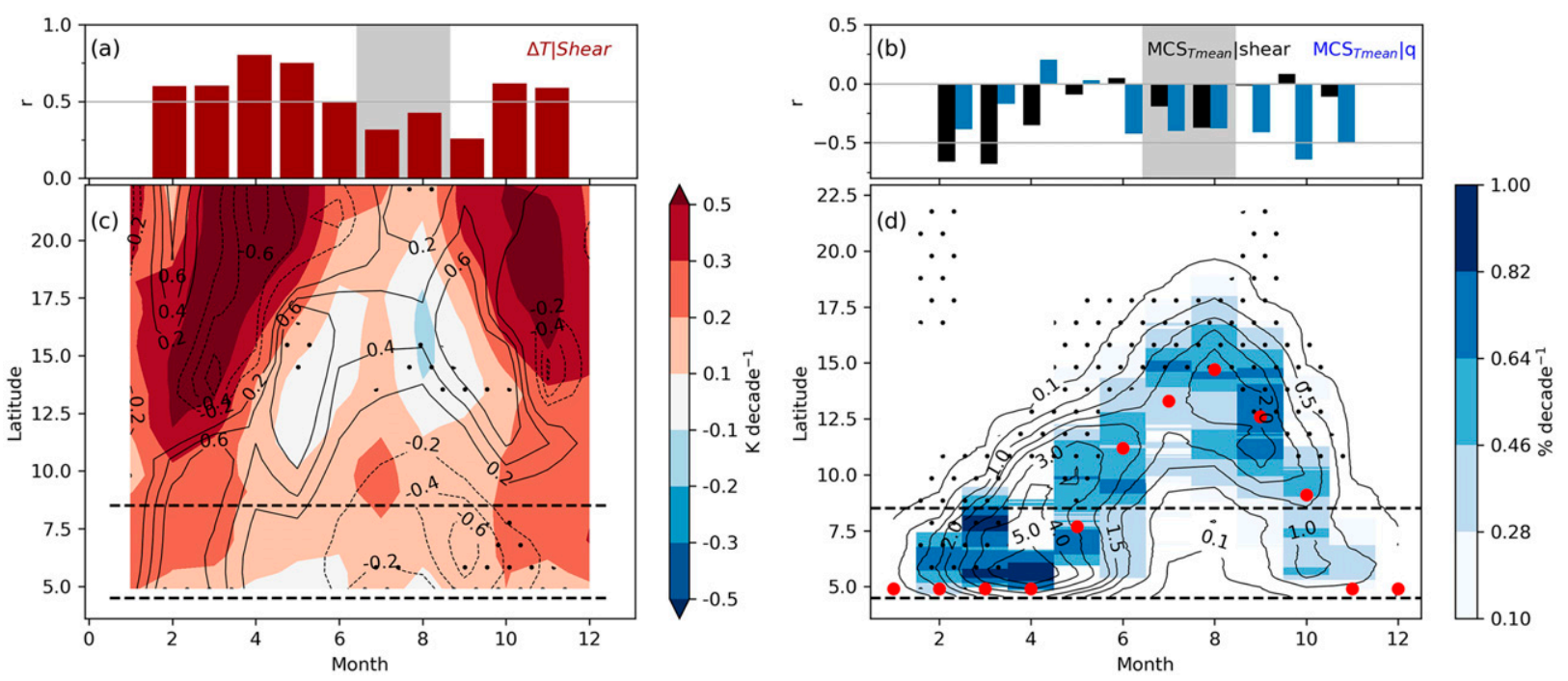

FIG. 2. Correlations of (a) $\Delta T$ with wind shear (600-925 hPa) and (b) mean MCS cloud-top temperatures with wind shear (black bars) and $925-\mathrm{hPa}$ specific humidity (blue bars). Here, $\Delta T$ is the difference between the NWA-maximum and SWA-minimum zonal-average 925-hPa temperatures (boxes in Fig. 1). Shear and specific humidity are the SWA maximum zonal average. Hovmöller plots show the 1983-2017 trend in (c) 925-hPa temperature (shading; $\mathrm{K}$ decade ${ }^{-1}$ ) and wind shear (contours; $\mathrm{m} \mathrm{s}^{-1} \mathrm{decade}^{-1}$ ) at $1200 \mathrm{UTC}^{2}$ and (d) significant trends in $-70^{\circ} \mathrm{C}$ cold cloud cover of storms larger $5000 \mathrm{~km}^{2}$ (shading; $\% ; p \leq 0.05$ ) and $1983-2017$ average $-70^{\circ} \mathrm{C}$ cloud cover (contours) at 1800 UTC. Dotted areas in (c) indicate significant positive trends in 925-hPa specific humidity and in (d) mark the areas of significant wind shear trend $(p \leq 0.05)$. Red dots mark the maximum 650-hPa zonal wind indicating the position of the AEJ. Note that between November and April the AEJ may be positioned south of $5^{\circ} \mathrm{N}$.

This variable is based solely on passive microwave estimates, which better preserves spatial rainfall structures than the full IMERG product. We note that GPM-IMERG rainfall over Africa has been found to be of a comparable quality to its predecessor TRMM3B42, showing a reasonable accordance with rain gauge data in southern West Africa (Dezfuli et al. 2017). In a detailed validation study against rain gauges in southern Ghana, (Maranan et al. 2020) identified a systematic underestimation of subdaily high-intensity rainfall. They found this underestimation to be aggravated by the gauge calibration for the final IMERG product, which additionally motivates our use of the passive microwave-only product for this MCS study.

For the comparison, we identified match-ups between microwave rainfall estimates and MCSs between 1800 and 2100 UTC from MSG images for the 2004-18 period. For each overlapping MCS, we extracted the maximum rainfall pixel, discarding cases as "non-convective" where this rate was less than $8 \mathrm{~mm} \mathrm{~h}^{-1}$, as in Klein et al. (2018). We also rejected any subsequent match-ups from the same day and region to avoid both double counting, and situations where previous MCSs have already altered the atmospheric conditions. This results in a dataset of 9001 MCSs. Associated prestorm atmospheric conditions are based on hourly ERA5 reanalysis data sampled at 1200 UTC, around the daily minimum in convective activity. The sampled ERA5 pixel corresponds to the location of the centered westernmost pixel of the respective MCS, approximately representing the front of the storm.

It should be noted that we are looking at MCS snapshots, which implies that the distribution of maximum rainfall from this approach is not representative for the maximum rainfall rate within an entire MCS life cycle.

\section{Observed trends in mesoscale convective systems}

\section{a. The seasonal cycle of trends}

In the following, we look at the annual cycle of trends in both MCSs and their potential drivers. Specifically we consider how positive trends in MCSs throughout the year can be linked to trends in two key drivers for MCS intensity: low-level atmospheric moisture and wind shear.

The moisture content in the lowest levels of the atmosphere is the most important source of energy for MCSs, as latent heat is released from the formation of hydrometeors in the mixedphase region of the storm, causing and maintaining strong convective updrafts [see review in Houze (2004)]. However, the updraft velocity (for which cloud-top temperatures are used as a proxy here) is, by approximation, a function of both the thermodynamic conditional instability of the surface air layer and a dynamical component that affects the rate at which this air is replenished by converging moist air from the surroundings (Nie et al. 2018). This dynamical component is strongly enhanced by a favorably sheared environment (Alfaro and Coniglio 2018).

To first establish the general link between the meridional temperature gradient and wind shear, we evaluate their interannual covariability in Fig. 2a. The meridional temperature difference $\Delta T$ and wind shear are well correlated (coefficient exceeding 0.5) from February to May, and again in October 
and November. These correspond to the months in which the AEJ (red dots in Fig. 2d) resides inside or at the border of the SWA domain. However, correlations with MCS intensity in Fig. $2 b$ show a dominant control of wind shear only from February to April (FMA), with a minimum coefficient of -0.73 in March. Stronger correlations with low-level moisture take over from June onward, and reach a minimum of -0.65 in October, indicating a change in convective regime. The dominance of low-level moisture control over wind shear prevails for June and September-November (J/SON). This encompasses the second rainy season, and hints at different storm drivers at play when comparing the early first and second rainy season over SWA.

The two rainy seasons are separated by the so-called Little Dry Season in July-August, when the monsoon rainband reaches its northernmost position and rainfall in SWA declines, as illustrated by the low average $-70^{\circ} \mathrm{C}$ cloud cover in Fig. 2 d. It should also be noted that there is no interannual correlation with either wind shear or low-level moisture in May (Fig. 2b), when the AEJ position is already farther north. This suggests a mixed convective regime within the analysis domain, with moisture control taking over in the southern parts, while wind shear can still be strong to the north, characterizing May as a transition period. Correspondingly, the MCS and shear trends are shifted toward the northern boundary of the SWA domain in this month (Figs. 2c,d).

Having established the dominance of shear (humidity) for explaining interannual variability in cold MCSs during FMA (J/SON), we now consider the seasonal cycle of their trends. Figure $2 \mathrm{c}$ shows that temperatures increased by more than $0.5^{\circ} \mathrm{C} \mathrm{decade}^{-1}$ in the Sahel on either side of the peak monsoon season. Taken together with the strong warming trends in the Sahara during the peak of the monsoon (T17; Vizy and Cook 2017), it is evident that maximum warming follows the northern edge of the monsoon rainband. Particularly before and during the start of the first rainy season in SWA during FMA, temperatures show a significant trend throughout the Sahel down to $12^{\circ} \mathrm{N}$. At those latitudes, soil moisture is limited at the end of the dry season and therefore evaporation cannot buffer the overall surface warming trend. Consistent with the annual cycle of temperature trends, we find a positive trend of lowlevel wind shear, displaced to the south where the meridional temperature gradient has increased (Fig. 2c, contours).

In general, latitudes with a significant trend in wind shear (Fig. 2d, dotted) overlap or lie just to the north of regions that show a significant increase in $-70^{\circ} \mathrm{C}$ cloud cover $>0.46 \%$ dec$\mathrm{ade}^{-1}$, an indicator for more frequent cold MCSs (Fig. 2d, shading). For SWA, this includes the early first rainy season, where a coherent trend in cold MCSs is visible in the vicinity of the AEJ maximum along the coast up to $7^{\circ} \mathrm{N}$. On the other hand, for the second rainy season, the shear trend lies well to the north of SWA. Instead, the weaker MCS trend during the second rainy season is accompanied by a positive trend in low-level moisture in SWA (Fig. 2c, dotted).

Finally, while the absolute trend in $-70^{\circ} \mathrm{C}$ cloud cover is strongest in March and April, this corresponds to an average relative trend over the full $1983-2017$ period of $63.9 \%$, in comparison to a relative increase of $153.8 \%$ in October and
November with respect to the average $-70^{\circ} \mathrm{C}$ cloud cover. This analysis confirms important positive trends in cold MCSs during both SWA rainy seasons, albeit linked to different drivers. The seasonality of trends is in line with the seasonal change in the dominant control of MCS intensity on interannual time scales, and suggests a strengthening of the climatologically prevailing conditions of a shear- or moisture-dominated convective regime. Based on the seasonal changes, we henceforth refer to atmospheric conditions that prevail during FMA as the "shear regime" and to conditions in J/SON as the "moisture regime." The commonly referred to "first rainy season" (March-June) thus contains a transition from the shear regime to the moisture regime.

\section{b. Spatial patterns of shear-and moisture-related trends}

We now consider the spatial distribution of trends from months representing shear-driven (March) and humidity-driven (October) trends. Figure 3 a reveals a widespread increase in wind shear over SWA in March that closely follows the southern boundary of strong warming across the Sahara and Sahel. The change in relative humidity, used here as an indicator for midlevel dryness, shows a strong negative trend across SWA, likely as a consequence of increasing temperatures to the north in the Sahel. This relationship seems to be consistent with Sahelian midlevel trends reported by T17 for the peak monsoon season in association with Saharan warming. They suggested midlevel drying in the Saharan air layer (SAL), which overlays the moisture-laden southwesterly monsoon wind, as another potential contributor to MCS intensification besides wind shear, although there is no consensus on the role of dry midlevels (e.g., Barnes and Sieckman 1984; Roca et al. 2005; James and Markowski 2010; Smith and Montgomery 2012).

Finally, considering the role of thermodynamic drivers for the increase in cold MCS cloud cover, Fig. 3c reveals almost exclusively negative trends in total column water vapor (TCWV) and CAPE over SWA. This provides additional evidence that MCS intensification trends in the first rainy season are likely shear-driven.

In contrast to March, during October (Fig. 4) there are widespread increases in TCWV, together with a local increase in surface temperatures of up to $0.4 \mathrm{~K}$. There is a clear positive response of wind shear to amplified Saharan warming similar to March (Fig. 4a), but this lies well to the north of the SWA domain. Positive trends in low-level moisture are also found in the MERRA-2 reanalysis, but located $500 \mathrm{~km}$ farther south, where ERA5 shows no trend, while TCWV trend magnitude and pattern correspond well (not shown), illustrating the uncertainty in inferring moisture trends from reanalyses. Locations of increased cold cloud cover in Fig. 4d lie predominantly equatorward of the AEJ and are statistically significant in areas associated with late afternoon maxima, often associated with topography and coastlines (cf. Fig. 1).

Figure 5 summarizes discussed trends for March and October over the SWA domain. Negative trends in the mean temperature of $-50^{\circ} \mathrm{C}$ MCS cloud cover (colder cloud tops used as an indicator for MCS intensification) show little difference between both months, with values of $-0.6 \mathrm{~K} \mathrm{decade}^{-1}$ in March and $-0.7 \mathrm{~K}_{\text {decade }}{ }^{-1}$ in October. However, while in 
a) $2 \mathrm{~m}$ temperature | $925-600 \mathrm{hPa}$ wind shear $\mid 650 \mathrm{hPa}$ wind vectors

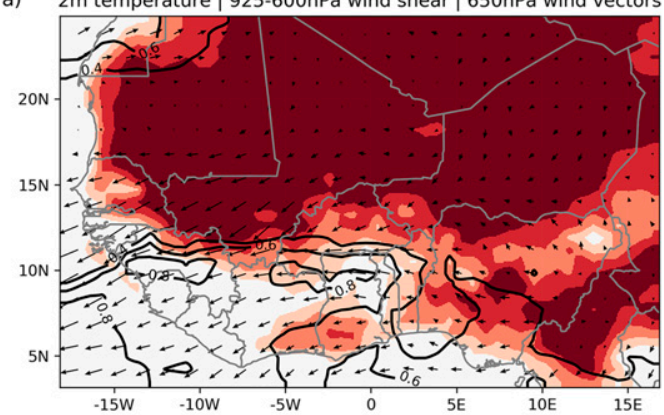

c)

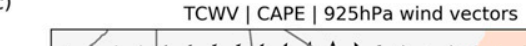

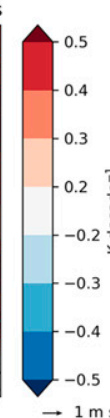

b)

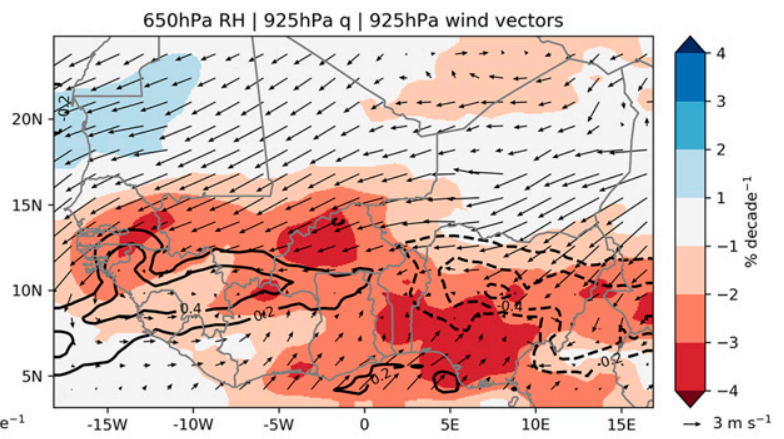

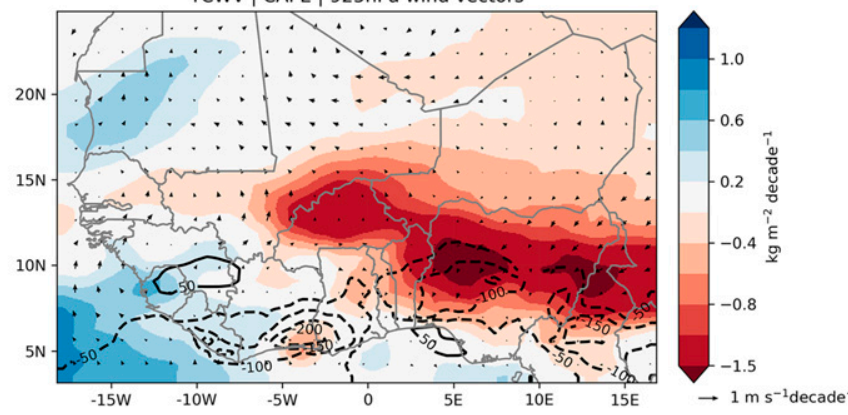

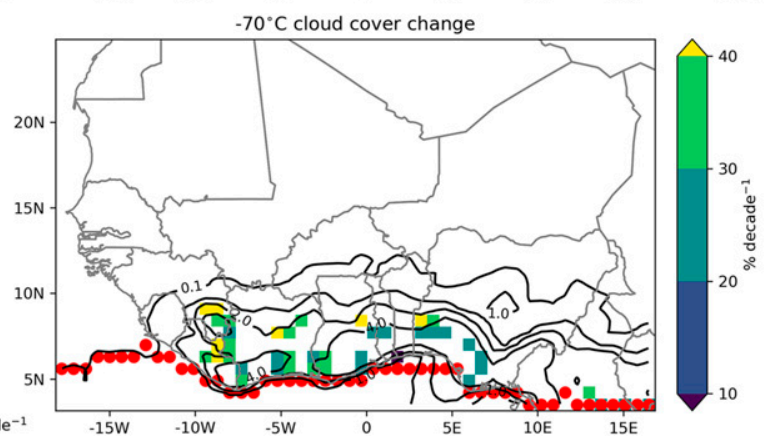

FIG. 3. March trends (1983-2017) for (a) 2-m temperature (shading; $\mathrm{K}$ decade ${ }^{-1}$ ), wind shear (contours; $\mathrm{m} \mathrm{s}^{-1}$ ), and 650 -hPa wind (vectors; $\mathrm{m} \mathrm{s}^{-1}$ decade $^{-1}$ ); (b) 650-hPa relative humidity (shading; \% decade ${ }^{-1}$ ) and 925-hPa specific humidity $\left(\right.$ contours; $\mathrm{g} \mathrm{kg}^{-1}$ decade $^{-1}$ ); (c) total column water vapor $\left(\mathrm{kg} \mathrm{m}^{-2}\right)$, CAPE $\left(\mathrm{J} \mathrm{kg}^{-1} \mathrm{decade}^{-1}\right)$, and 925-hPa wind (vectors; $\left.\mathrm{m} \mathrm{s}^{-1} \mathrm{decade}^{-1}\right)$; and (d) change (shading) and average (contours) of $-70^{\circ} \mathrm{C}$ cloud cover. Red dots mark the the position of the AEJ as in Fig. 2. Wind vectors in (b) depict the mean 925 -hPa wind field $\left(\mathrm{m} \mathrm{s}^{-1}\right)$.

March (Fig. 5a) wind shear increased significantly by $0.5 \mathrm{~m} \mathrm{~s}^{-1}$ decade $^{-1}$, it shows a weak decrease in October (Fig. 5b). The linear regression for TCWV (blue dashed line), for which trends show a better agreement in the reanalysis datasets than for low-level moisture, indicates no trend in March while the October trend is significant with $0.5 \mathrm{~kg} \mathrm{~m}^{-2}$ decade $^{-1}$ (Figs. 5c,d). When instead considering low-level moisture, we find positive trends of $0.15 \mathrm{~g} \mathrm{~kg}^{-1}$ for both months, but similarly only a significant one in October (not shown). We therefore conclude that an increase in total available atmospheric moisture rather than shear is likely to dominate MCS trends in October, albeit with considerable quantitative uncertainties. March trends, on the other hand, appear to be linked to a more sheared environment.

\section{c. MCS frequency and potential links to rainfall trends}

Having established the importance of different MCS trend drivers before and during the two rainy seasons, we next consider relationships between the frequency of all MCSs, cold MCSs, and rainfall. The monthly climatology of MCS frequency (number of individual MCSs at 1800 UTC and averaged across SWA) at different temperature thresholds is presented in Fig. 6a. The number of MCSs shows a pronounced annual cycle with frequency peaks in April and October. Strikingly, the fraction of cold MCSs surpasses $40 \%$ during March-May (MAM; Fig. 6b), whereas it stays below 20\% in $\mathrm{J} / \mathrm{SON}$. This illustrates the prevalence of colder, more intense storms during the early first rainy season. This is in line with
Maranan et al. (2018), who inferred from TRMM rainfall radar data that the majority of rainbearing systems with deep and wide convective cores occurs in MAM. They found that the number of less organized, local thunderstorms gradually increases over the year, reaching a maximum in the second rainy season.

Comparing the trends for all and cold MCS numbers in Figs. $6 c$ and $6 d$, we only find a significant $(p \leq 0.05)$ increase of all MCS frequencies in June, October, and November (J/ON); months associated with moisture control. For cold MCSs on the other hand, the trend is significant for all months except JulySeptember and December. The average relative trend in cold MCS numbers for $\mathrm{J} / \mathrm{ON}$ with $+33.9 \%$ per decade is notably larger than the $21.3 \%$ per decade for the shear-regime months FMA (Fig. 6d).

The fact that only the cold MCS subgroup shows significant trends during the shear-dominated part before and early in the first rainy season suggests that it is directly linked to MCS intensification (i.e., stronger convection and therefore higher storm tops). This is particularly true for April and the transition month May, for which the trend in cold MCSs per day surpasses the trend in all MCSs, with over 0.18 per decade. For $\mathrm{J} / \mathrm{ON}$, the question of whether trends are predominantly associated with increases in MCS intensity or frequency is less clear.

Following (Mohr and Zipser 1996), we test the significance of MCS intensification for both regime periods, based on a two-tailed Mann-Whitney-Wilcoxon test on the cumulative 


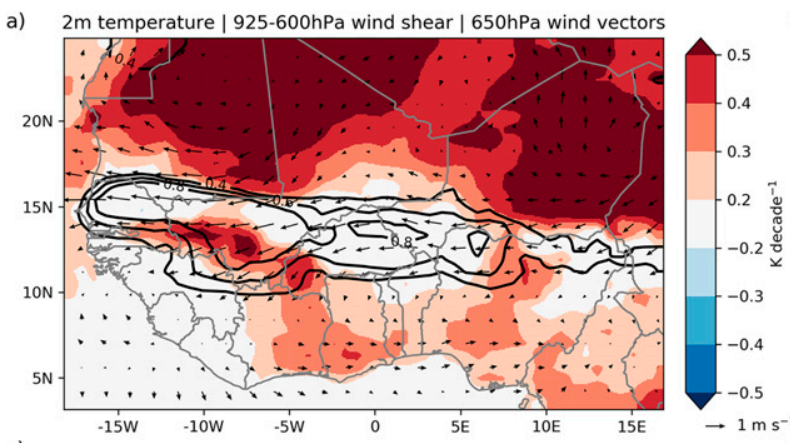

c) TCWV $\mid$ CAPE $\mid$ 925hPa wind vectors

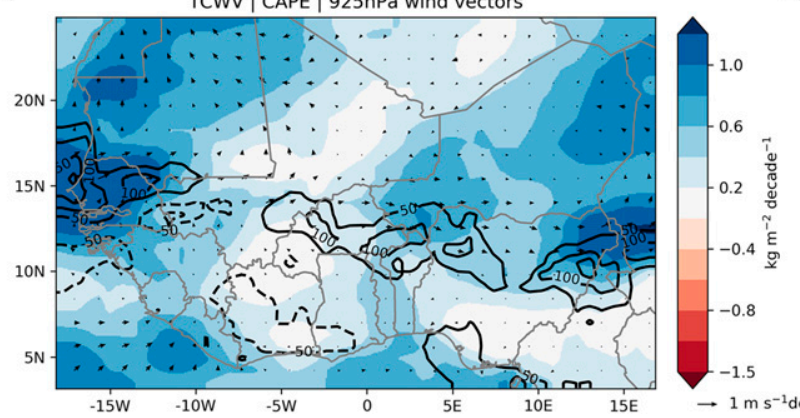

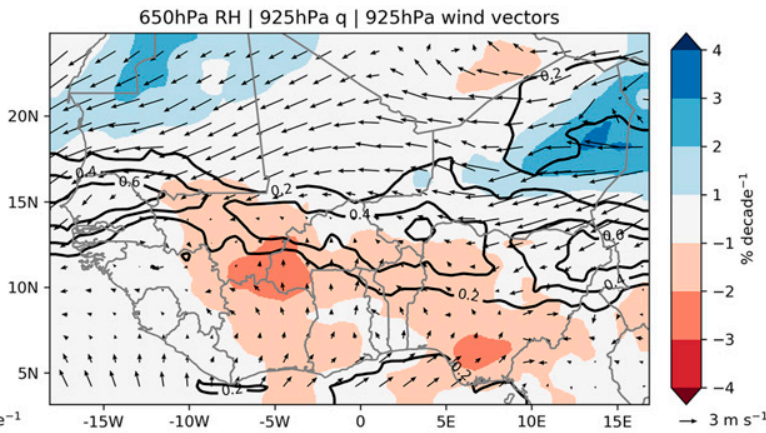

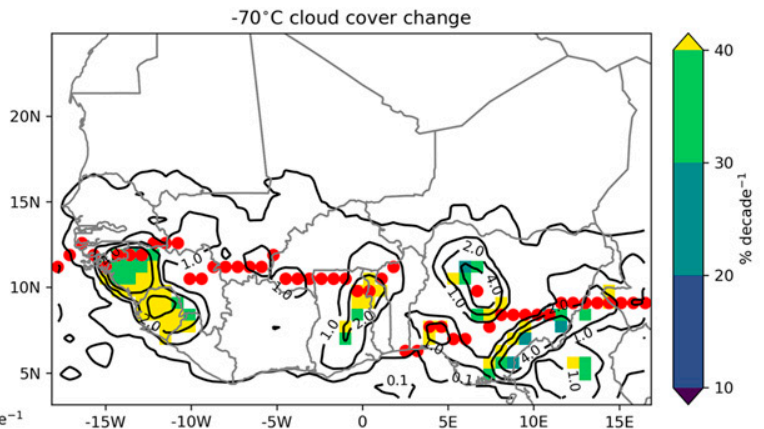

FIG. 4. As in Fig. 3, but for October.

distribution functions of cold MCS area size. The increase during FMA in cold MCS area is significant with respect to both the 1980s and 1990s (with $p<0.001$ ). The $\mathrm{J} / \mathrm{ON}-70^{\circ} \mathrm{C}$ MCS area change on the other hand is only significant for the $1980 \mathrm{~s}$ at the 0.05 level $(p=0.048)$ and insignificant for later time periods $(p>0.4)$. Therefore, a strong contribution from overall MCS frequency (rather than intensity) increases seems likely for J/ON (Fig. 6c) given the high temperature threshold that defines "MCSs" here.

T17 showed for the Sahel that MCSs identified at higher temperature thresholds correlate well with trends and interannual variability of total rainfall amounts, while $-70^{\circ} \mathrm{C} \mathrm{MCSs}$ (a)

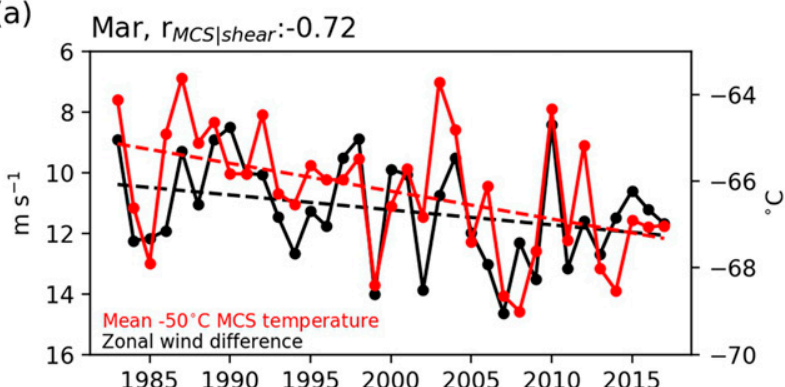

(c) Mar, $\mathrm{r}_{\text {MCS|TCWV: }-0.04}$

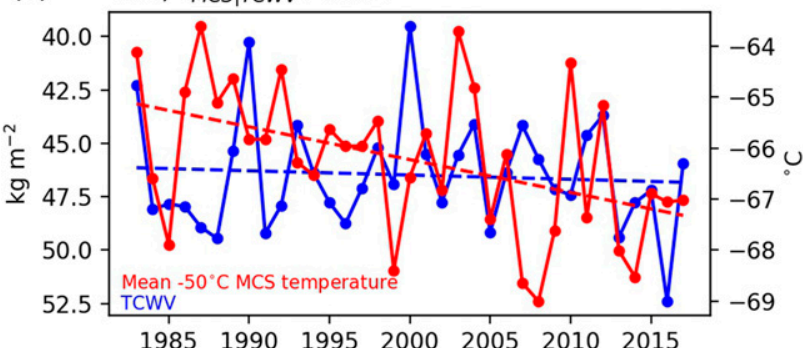

(b)

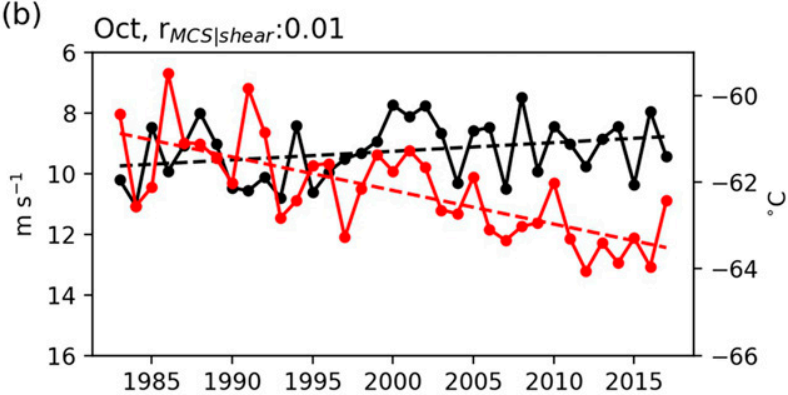

(d) Oct, $r_{M C S \mid T C W V:-0.61}$

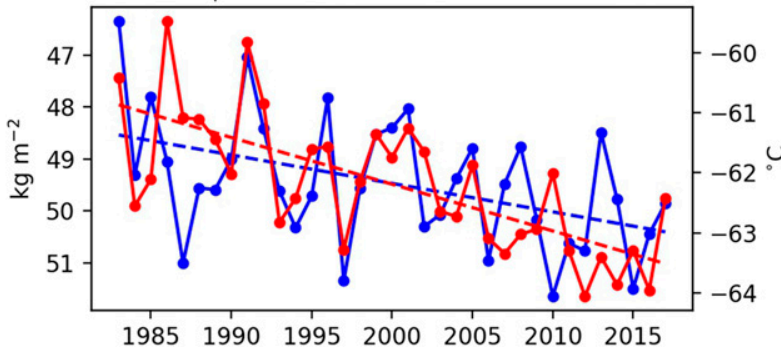

FIG. 5. Time series comparing (a),(c) March and (b),(d) October trends for MCS mean temperatures (red; $C^{\circ}$ ), wind shear (black; $\mathrm{m} \mathrm{s}^{-1}$ ), and total column water vapor (blue; $\mathrm{kg} \mathrm{m}^{-2}$ ). Note the flipped $y$ axis for humidity and wind shear. Titles show the correlation coefficients between variables as in Fig. 2, and dashed lines represent line of best fit. 

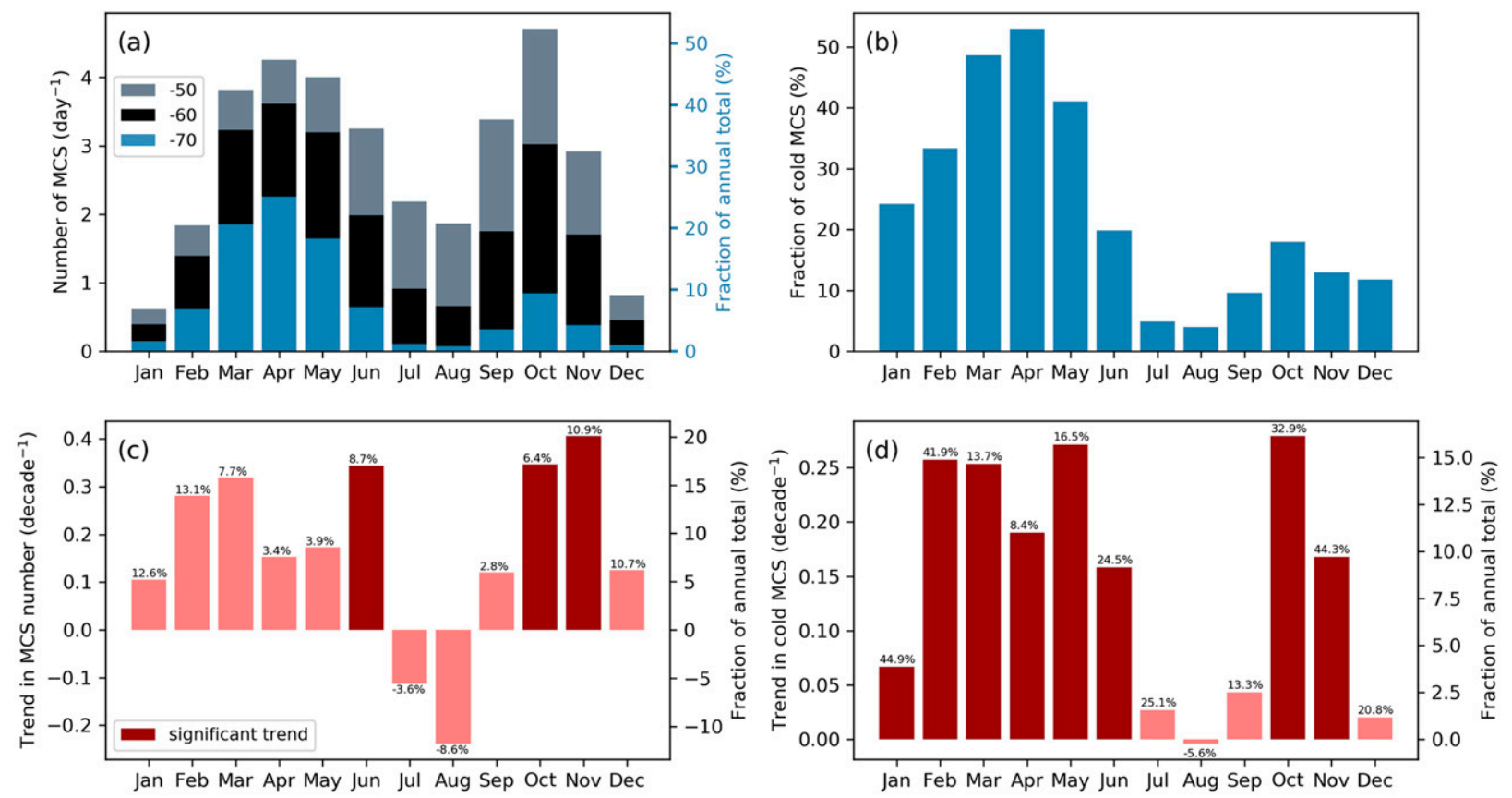

FIG. 6. Average annual cycle (1983-2017) of MCSs at 1800 UTC within the SWA box showing (a) the monthly average of MCS number per day at different temperature thresholds (left axis) and contribution to the annual total of cold $\left(-70^{\circ} \mathrm{C}\right) \mathrm{MCSs}($ right axis; \%), (b) fraction of all $\left(-50^{\circ} \mathrm{C}\right)$ MCSs $(\%)$ that are cold, and trends in MCS numbers (left axis) for (c) all MCSs and (d) cold MCS (decade $\left.{ }^{-1}\right)$. Bar percentages in (c) and (d) indicate the trend per decade relative to the 1983-2017 average. Significant trends $(p \leq 0.05)$ in (c) and (d) are marked in dark red and the right axis shows the fractional contribution to the annual trend.

better reflect changes in extreme rainfall events. Assuming this relationship holds in SWA, we might expect a significant trend in total rainfall during the second rainy season, and a trend toward more daily extremes in the first rainy season.

Sanogo et al. (2015) evaluated SWA rainfall from rain gauge data for 1980-2010 and indeed found strongest positive, albeit nonsignificant, trends in total precipitation in July and October and a significant trend in November. Considering all months, only the annual total precipitation on days exceeding the 95th percentile-a measure for the occurrence of extreme events-showed a significant trend in SWA, but this was not evaluated by season. Concentrating on daily rainfall extremes, Nkrumah et al. (2019) furthermore show that during the first rainy season (March-July) the average number of wet days remained fairly constant since the 1980 s, while average rainfall amounts on wet days increased, particularly in coastal regions, by about $10 \%$ since 1990 . The lack of a significant trend in total rainfall amounts in the first rainy season is similarly noted by Bichet and Diedhiou (2018) using remotely sensed rainfall estimates. At the same time, they emphasize a shift in rainfall distribution toward more intense but less frequent events. For the second rainy season they find a clear upward trend in rainfall totals, which they attribute to a combination of more frequent and more intense rainfall events.

Those studies do not entirely agree on the significance of trends in rainfall totals in SWA. However, taken together with our analysis of MCS trends, they do paint a broadly consistent picture. Before and early in the first rainy season, we infer that storms are becoming more intense. In the second rainy season, we propose that storms are predominantly becoming more frequent with weaker intensity increases after the 1980s, which together may be driving increases in seasonal rainfall.

\section{Climatological storm environments over southern West Africa}

\section{a. The annual cycle of MCS and rainfall intensity}

We now evaluate in more detail how the large-scale convective regime over SWA changes over the seasonal cycle, which ultimately sets the climatological boundary condition for observed MCS trends.

Figure 7a illustrates that over the course of the year, average MCS temperatures exhibit considerable differences over SWA with the coldest storms occurring before and early in the first rainy season from March to May, whereas SeptemberNovember storms are on average $5^{\circ} \mathrm{C}$ warmer. This implies that spring MCSs are more convectively intense than their counterparts in autumn; however, comparison with monthly observed rainfall (Fig. 7b) shows that those months are not simultaneously associated with highest total rainfall amounts (cf. June-July and September-October).

Cold MCSs predominantly occur under conditions with high CAPE (Fig. 7a) and high shear (Fig. 7c), while the rainiest months are characterized by high TCWV (Fig. 7b). At the same time, low-level moisture is lower during rainiest months 

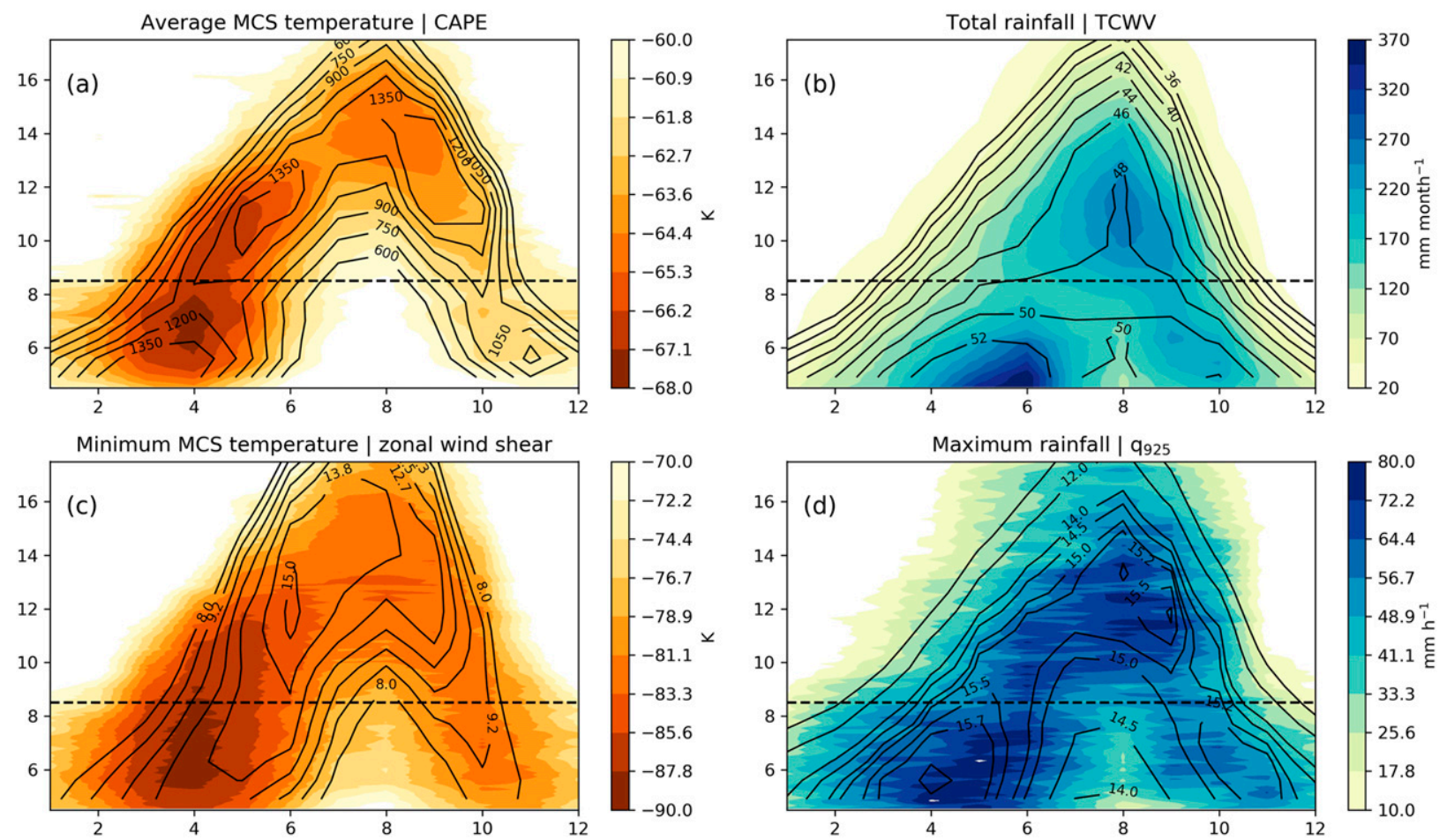

FIG. 7. Average annual cycle across $10^{\circ} \mathrm{W}-12^{\circ} \mathrm{E}$ for (a) average MCS temperature (contours; K) and CAPE (J kg ${ }^{-1}$; contours),(b) GPM monthly rainfall (1981-2017; shading; mm month ${ }^{-1}$ ) and total column water vapor $\left(\mathrm{kg} \mathrm{m}^{-2}\right.$; contours), (c) minimum MCS temperature (shading; K) and 650-925-hPa zonal wind difference ( $\mathrm{m} \mathrm{s}^{-1}$; contours), and (d) maximum MCS rainfall (shading; $\mathrm{mm} \mathrm{h}^{-1}$ ) and 925-hPa specific humidity (contours; $\mathrm{g} \mathrm{kg}^{-1}$ ).

compared to those with the coldest MCSs. The latter are also associated with highest instantaneous rainfall rates (Fig. 7d), which occur in March-May as a consequence of a high-CAPE, high-shear environment with increased low-level moisture.

\section{b. The shift from shear regime to moisture regime}

We now consider differences in the regional circulation when moving from a shear regime to a moisture regime in SWA. Figure 8 illustrates the mean state of key variables for the months of March and June. In March (Fig. 8a), the northern flank of the AEJ sits just above SWA. CAPE is maximized over the region, with an average of $1.17 \mathrm{~kJ} \mathrm{~kg}^{-1}$, while average TCWV is below $50 \mathrm{~kg} \mathrm{~m}^{-2}$. The vertical stratification of relative humidity depicts low-level moist air that is occasionally advected inland from the Gulf of Guinea and undercuts extremely warm and dry air between 750 and $650 \mathrm{hPa}$, leading to capping conditions that favor the accumulation of CAPE. During this time, the peak in fractional cloud cover for all (solid line; integral is $100 \%$ ) and cold (dotted line; integral is $100 \%$ ) MCSs occurs over the same region. Across the SWA domain, $\sim 30 \%$ of the MCS cloud cover belongs to the "cold" category (not shown), staying below $-70^{\circ} \mathrm{C}$, with $45 \%$ of individual MCSs reaching cold characteristics (Fig. 6b).

This picture markedly changes over SWA from June onward (Fig. 8b), when the AEJ moves northward and takes the peak of cold MCSs with it. June shows shear regime conditions north of $10^{\circ} \mathrm{N}$ in the Sahel. Over SWA, more stable, moist conditions prevail on the southern flank of the AEJ, clearly shown by more homogeneous conditions of relative humidity throughout the atmospheric column. This change in convective regime is also illustrated by a gradual equatorward decrease of CAPE and a mean TCWV of $51.07 \mathrm{~kg} \mathrm{~m}^{-2}$, up from $45.1 \mathrm{~kg} \mathrm{~m}^{-2}$ in March. The humid stratification in combination with lower average CAPE is indicative of frequent instability and deep convection that characterize the moist regime. In consequence, we find a peak in cloud cover for the total MCS sample over SWA, which is of a warmer, less explosive type, with only $12 \%$ of the cloud cover associated with cold MCSs. Wind vectors now indicate a widespread ascent region over SWA in the monthly mean due to frequent convection.

However, while rainfall events occur more frequently in the moist regime due to weaker convective inhibition, less entrainment, and more TCWV compared to the shear regime, fewer such events reach MCS size and those MCSs that develop tend to be less intense (cf. Maranan et al. 2018). The moisture regime lacks the strong dry capping layer, which over West Africa coincides with an increase in wind shear at the location of the AEJ. For the Sahel, this difference in convective regime poleward and equatorward of the AEJ was already described in detail by Parker et al. (2005). For the equatorward region they identify a thermodynamic profile that is closer to a pseudoadiabat, which they consider consistent with a strong and frequent influence of deep moist convection. On the poleward side of the AEJ, where the SAL overlays the 
(a) March | CAPE: 1.17 | TCWV: 45.1

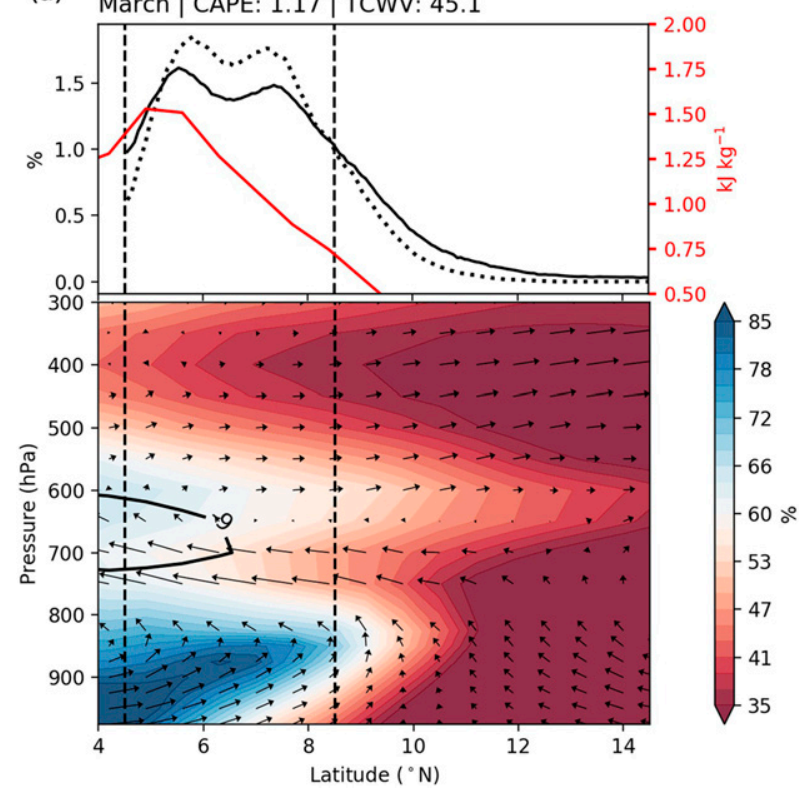

(b)

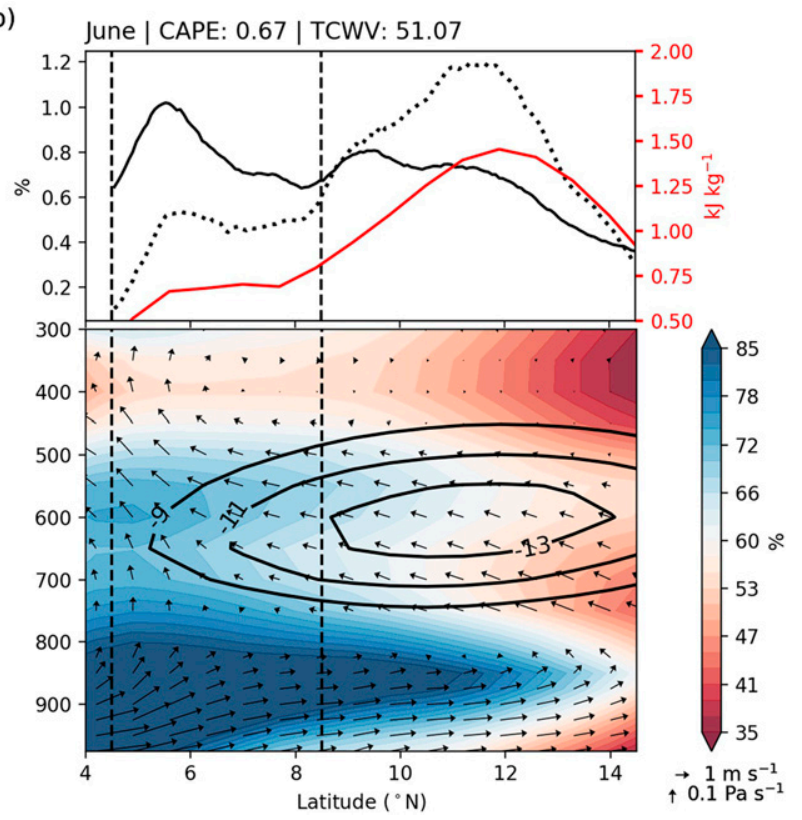

FIG. 8. Monthly average 1200 UTC cross sections for (a) March and (b) June between $10^{\circ} \mathrm{W}$ and $12^{\circ} \mathrm{E}$ of relative humidity (shading; \%), zonal wind of the AEJ (contours), and meridional wind vectors ( $v$ wind in $\mathrm{m} \mathrm{s}^{-1}$; - omega in $\mathrm{Pa} \mathrm{s}^{-1}$; the $w$ component was multiplied by 10 for better visibility). The top line plots show meridional fractional cloud cover of all (solid line; integral over latitudes is $100 \%$ ) and intense (dotted line; integral over latitudes is $100 \%$ ) MCSs at 1800 UTC (\%), and CAPE (red; $\mathrm{kJ} \mathrm{kg}^{-1}$ ). The title shows SWA domain (vertical dashed lines) averages for CAPE $\left(\mathrm{kJ} \mathrm{kg}^{-1}\right)$ and total column water vapor $\left(\mathrm{TCWV} ; \mathrm{kg} \mathrm{m}^{-2}\right)$.

monsoon layer, they find strong baroclinicity and high conditional instability; a region for which they assume intense but only sporadic deep convection.

Those contrasting convective regimes similarly affect SWA. Consequently, the intensification of wind shear via temperature gradients can only affect MCSs in SWA when the zone of increased instability and shear sits over the region. Those conditions are given underneath and at the northern flank of the AEJ. This changes into a more moisture dominated regime as the AEJ moves past SWA during the transition month of May (cf. Fig. 2d). The observed trends are therefore highly sensitive to the timing of the movement of the entire monsoon system and MCS trends can be expected to be linked to the prevailing convective regime.

\section{Atmospheric environment at event time}

\section{a. Dependence of drivers for cold MCSs on the atmospheric regime}

So far, we considered the climatological conditions that foster seasonal differences in MCS intensities. We conclude our analysis by considering the sensitivity of MCS intensity to its drivers at the event time scale. We first evaluate whether preevent drivers of MCS intensity differ between the two core regime periods, FMA and SON. For this, we composite preconvective atmospheric conditions from ERA5 at 1200 UTC on storm days ( $-50^{\circ} \mathrm{C}$ MCSs between 1800 and 2100 UTC) at storm location.

In Figs. 9a and 9b, we show prestorm low-level moisture and zonal wind shear profiles for the coldest (most intense) and the warmest (weakest) decile of sampled MCSs for both seasonal regimes. On average, event days in FMA are slightly moister than their SON equivalent at low levels, and exhibit stronger shear. This is consistent with climatological differences between the two regimes (Fig. 7). However, in both FMA and SON, profiles preceding the most intense storms exhibit similar differences compared to the least intense events (Figs. 9c,d). Specifically, more intense convection occurs when low-level moisture is anomalously large and the AEJ is stronger, coinciding with anomalously dry midlevels.

This commonality indicates that the coldest, most intense MCSs are fostered by comparable atmospheric conditions, irrespective of season. Our results based on environmental zonal wind shear suggest that the vast majority of MCSs during SON do not experience strong shear (and therefore tend to be less organized). We therefore conclude that it is most likely moisture availability that dominates overall MCS characteristics and trend statistics during that season. However, it is important to bear in mind that environmental and storm-relative shear can differ considerably (e.g., Nicholls and Mohr 2010) such that our shear proxy may not be representative for every case.

\section{b. Sensitivity of MCS intensity to low-level moisture and shear}

Based on our result that, on average, positive anomalies of both low-level humidity and wind shear seem to be important preconditions for the development of cold MCSs irrespective of season, we now examine their relative importance across the 
(a)

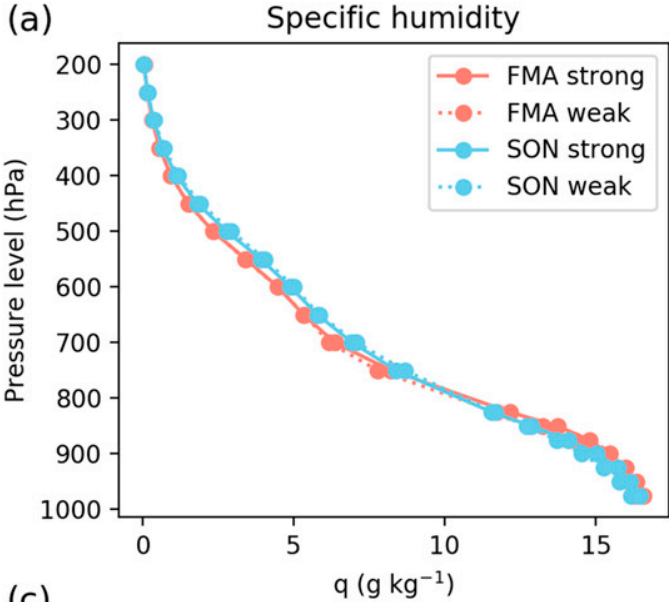

(c)

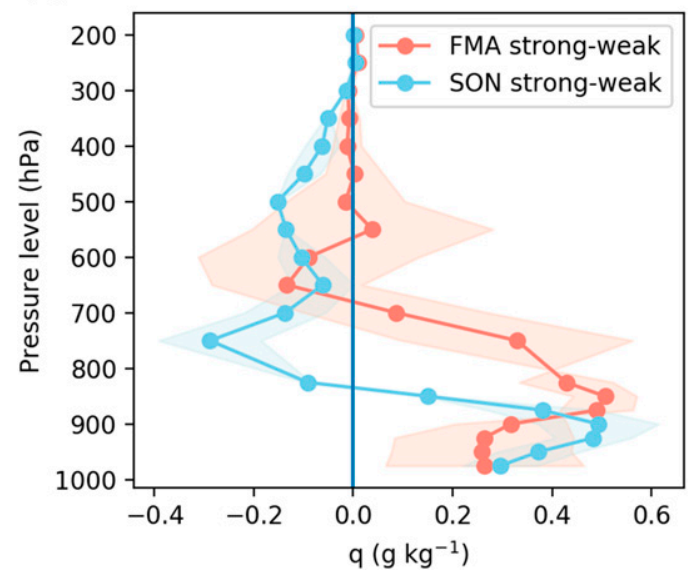

(b)
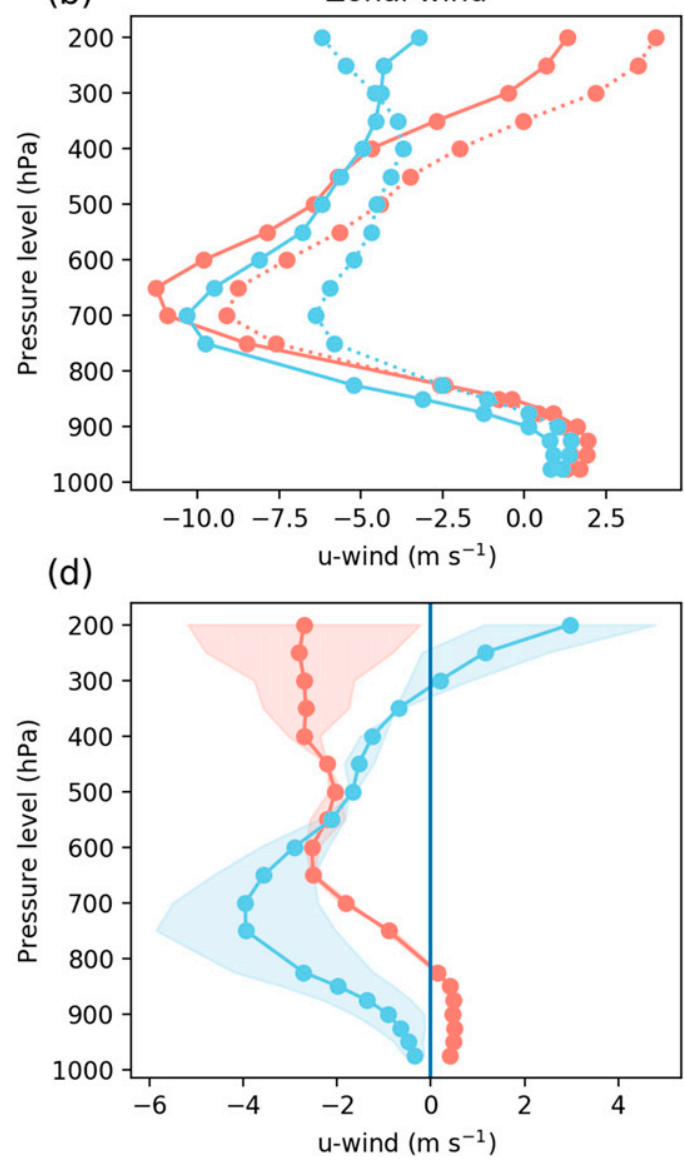

FIG. 9. (top) Average vertical profiles and (bottom) differences of $1200 \mathrm{UTC}$ (a),(c) specific humidity ( $\mathrm{g} \mathrm{kg}^{-1}$ ) and (b),(d) zonal wind $\left(\mathrm{m} \mathrm{s}^{-1}\right)$ composited on days with intense (coldest decile of mean MCS temperature) and weak (warmest decile of mean MCS temperature) MCSs for February-April (FMA; red) and SeptemberNovember (SON; blue).

entire population of MCSs (full SWA domain, FebruaryNovember). Again, we use the sample of ERA5 atmospheric conditions at 1200 UTC at the location where MCSs that occur later in the day, between 1800 and 2100 UTC.

Figures 10a and 10b show two-dimensional histograms of minimum temperature (as a proxy for convective intensity) and maximum precipitation respectively as a function of prestorm zonal wind shear and low-level humidity.

As expected, they demonstrate that MCSs tend to get colder and produce more intense precipitation when ERA5 depicts both increased low-level moisture and increased wind shear preceding the storm. The triangles up (down) in both plots mark the average conditions for the 90th (10th) percentile intensity MCSs as were used to compute Fig. 9 anomalies. During both convective regimes, MCS intensification follows a fairly similar path, with slightly less contribution from shear in FMA, when average wind shear values are already high.

Data from Fig. 10b are replotted in Figs. 10c and 10d in order to more clearly show the relative sensitivities of maximum precipitation to wind shear and humidity separately. Within a given wind shear bin (Fig. 10c), the spread in maximum precipitation is significantly smaller than within a low-level humidity bin (Fig. 10d). Considering the full range of conditions, the average interquartile spread in rainfall is $2.8 \mathrm{~mm} \mathrm{~h}^{-1}$ for given wind shear, and $6.8 \mathrm{~mm} \mathrm{~h}^{-1}$ for given humidity. This shows that for our sample, the sensitivity of MCS maximum rainfall to wind shear is about 2.4 times higher than to preconvective low-level moisture. The sensitivity factor varies between 2 and 3, depending on the number of chosen bins and approach of averaging over the population of MCSs (not shown), but robustly confirms a higher sensitivity of MCS intensity to shear than to low-level humidity. In Fig. 10b, even relatively dry conditions between 13 and $14 \mathrm{~g} \mathrm{~kg}^{-1}$ show a mean maximum precipitation of over $29 \mathrm{~mm} \mathrm{~h}^{-1}$ as long as wind shear is $\geq 15 \mathrm{~m} \mathrm{~s}^{-1}$. However, it is important to remember that the sensitivity factor is based on the condition that an MCS developed in the first place, and therefore by definition, only considers environments that are favorable for convection and organization on the mesoscale. Here, we find a specific humidity threshold of about $12.5 \mathrm{~g} \mathrm{~kg}^{-1}$ at $925 \mathrm{hPa}$ (not shown), 


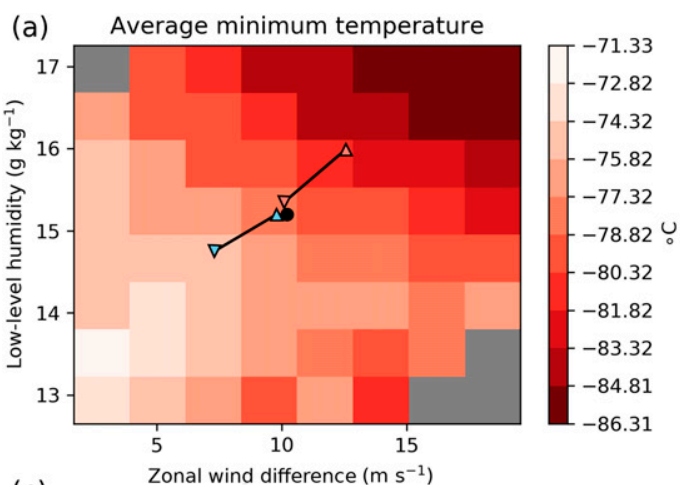

(c)

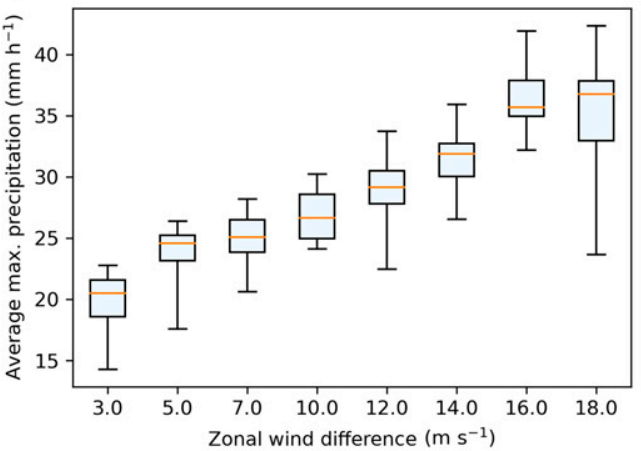

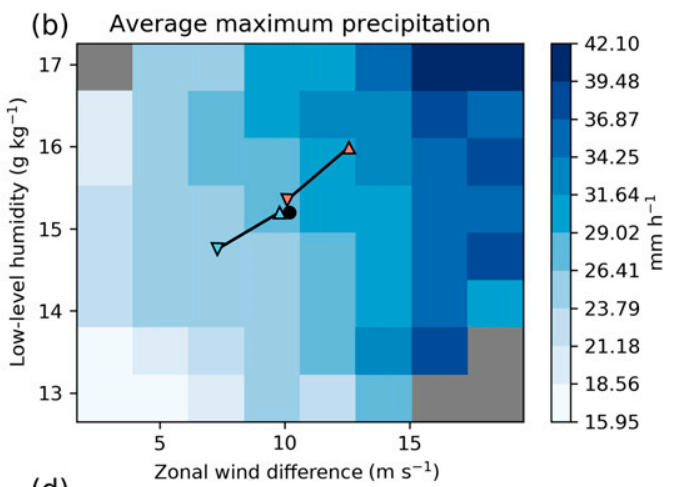

(d)

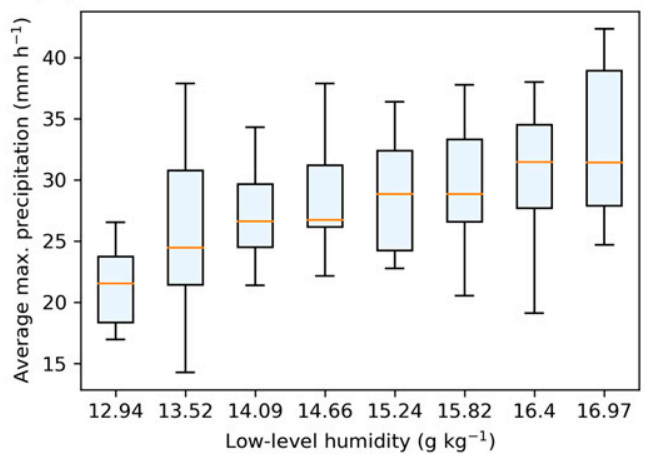

FIG. 10. 2D histograms for (a) average minimum temperature and (b) average maximum precipitation as a function of prestorm $925-\mathrm{hPa}$ specific humidity and 650-925-hPa absolute zonal wind difference for 9001 MCSs over SWA. All bins are evenly spaced and span the range between the 1st and 99th percentiles for the respective variable. Where fewer than $10 \mathrm{MCSs}$ are observed within a bin, the pixel is shaded gray. The black dot indicates the average of all MCSs: upward (downward) triangles indicate average coldest (warmest) deciles for MAM (red) and SON (blue). Boxplots are produced from (b), illustrating the spread of average maximum precipitation (c) per wind shear bin and (d) per low-level humidity bin. Boxes span the interquartile range and whiskers extend to the minimum and maximum values.

below which we did not find any MCSs to include in our sample.

As described before, wind shear is an important factor for MCS precipitation via its effect on horizontal MCS growth and on the inflow of unstable boundary layer air. In Fig. 11 we therefore explore how wind shear affects the relationship between available low-level moisture and precipitation intensity. Figure 11a (bars) illustrates that the probability of an MCS to produce rainfall above the 95 th percentile threshold increases from $2.5 \%$ to $12.3 \%$ over the range of observed wind shear conditions. This increase in rainfall intensity is accompanied by a drop in minimum MCS temperature with stronger wind shear (Fig. 11b). At the same time, the slope of the linear regression $\delta P_{\max } / \delta q_{925}$ in Fig. 11a shows that MCS maximum rainfall intensity doubles per available unit of prestorm lowlevel specific humidity if wind shear is increased from 5-7.5 to over $15 \mathrm{~m} \mathrm{~s}^{-1}$.

Finally, Fig. 11b shows that moisture convergence ahead of an MCS is positively correlated with wind shear, illustrated here by the difference in low-level moisture $\Delta q_{925}$ before and at storm time. The moisture increase reaches an average of $0.6 \mathrm{~g} \mathrm{~kg}^{-1}$ for shear conditions between 16 and $18 \mathrm{~m} \mathrm{~s}^{-1}$. This behavior was also noted by Maranan et al. (2018), who identified particularly pronounced moisture convergence for storm types associated with stronger shear, and pointed out that wind shear, rather than precipitable water, is the best predictor for storm characteristics in SWA.

These results are consistent with wind shear having a direct effect on the intensity of storm circulations and on the efficiency with which an MCS can extract available moisture from its surroundings to produce rainfall. In this context, it should be remembered that our measures of MCS drivers are obtained from atmospheric reanalysis in a sparsely observed region. The ERA5 depiction of the environment in which MCSs occur may differ substantially from reality when considering an individual event. However, when averaging over thousands of West African MCSs, we have found that ERA5 presents a high level of physical consistency with expectations.

\section{Discussion and conclusions}

In this study, we evaluated MCS trends in southern West Africa and identified important dynamical and thermodynamical drivers throughout the annual cycle. An important question was whether similar mechanisms to those found by Taylor et al. (2017) in the Sahel might also play a role for MCSs 

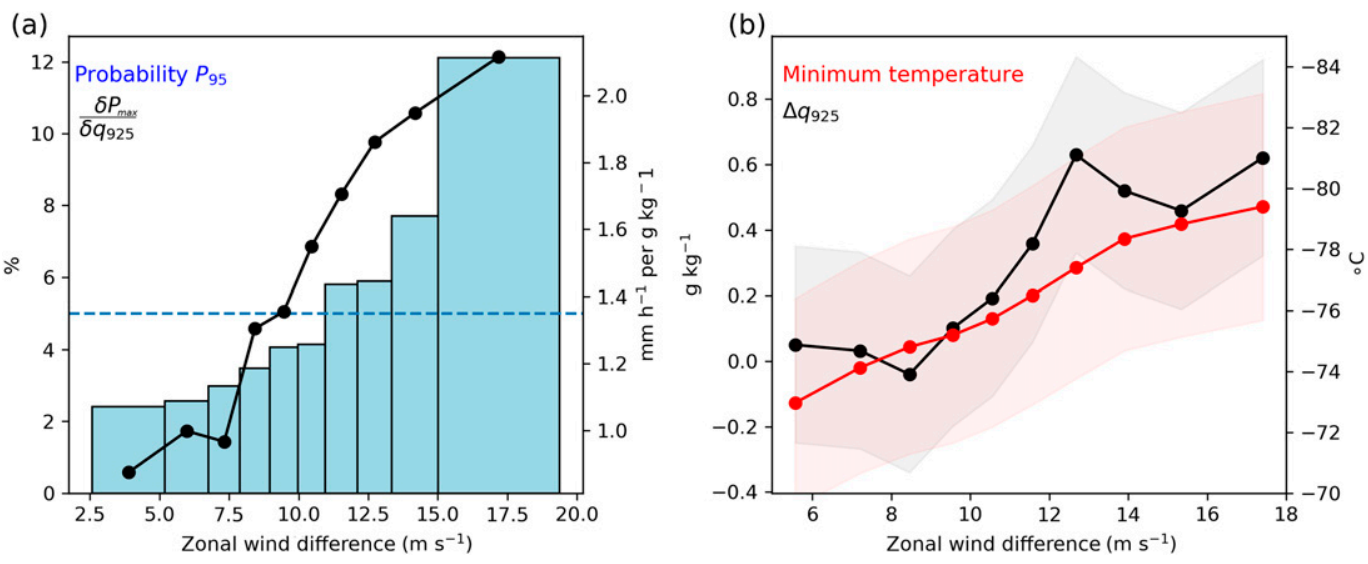

FIG. 11. Dependency on absolute zonal wind difference $(650-925 \mathrm{hPa})$ of (a) probability of extreme rainfall $\left(P_{95}\right)$ (\%; $\geq 95$ th percentile of MCS rainfall; bars) and the slope of the linear regression of MCS rainfall and $925-\mathrm{hPa}$ specific humidity ( $\mathrm{mm} \mathrm{g} \mathrm{h}^{-1} \mathrm{~kg}^{-1}$; black) as well as (b) MCS minimum temperature $\left({ }^{\circ} \mathrm{C}\right.$; red) and the change in prestorm 925-hPa specific humidity between 1200 UTC and $1800 \mathrm{UTC}\left(\Delta q_{925}\right)\left(\mathrm{g} \mathrm{kg}^{-1}\right.$; black). Ranges mark $\pm 2 \sigma$, and bins are equally populated.

in southern West Africa (SWA). Following their methodology, we identified trends in all MCSs, and a subgroup representing colder, more intense MCSs, based on 34 years of cloud-top temperature data, in combination with reanalysis data and rainfall estimates. We found that enhanced warming trends extend from the Sahara down into the Sahel outside of the local rainy season, and are evident in all months except December. Generally, West African MCSs are under the influence of increasing temperature gradients, and associated positive trends in wind shear, throughout the annual cycle. However, for SWA, this is only true before and during the early first rainy season. From June onward, interannual variability is more strongly affected by atmospheric moisture availability and associated instability that is frequently released. Hence, identified upward trends in humidity may be driving large-scale MCS trends during the second rainy season.

We attribute this behavior to the distinct moist convective regimes on either side of the AEJ. Equatorward of the jet, weak shear, low CAPE, and moister midlevels favor weaker MCSs. Poleward of the jet, humid low levels, strong shear, high CAPE, and dry midlevels favor cold MCSs. The MCS trends that we observe are then directly linked to a strengthening of the climatologically prevailing convective regimes that define different phases of the West African monsoon progression.

Those regimes were already identified with a focus on the Sahelian monsoon months in several studies (Parker et al. 2005; Vizy and Cook 2018; Mohr and Thorncroft 2006), and we find them to be of similar importance for MCSs over SWA, and outside of peak monsoon months. In particular, the change in convective regime following the poleward migration of the African easterly jet and the monsoon rainband causes a decrease in the fraction of cold MCSs over the course of the year, as described by Nicholls and Mohr (2010) for the May-October period. This is also in line with Maranan et al. (2018), who quantified the annual distribution of MCSs and other rainfall types. They found the deepest, most organized MCSs in
March-May (early first rainy season), whereas MCSs with lower cloud tops and isolated storms dominate the SeptemberOctober period (second rainy season). Indeed, from the entire West African monsoon cycle, we find the MCSs that develop over SWA from March to May to be the most convectively intense, featuring highest instantaneous rainfall rates.

Linked to that, the strongest absolute trends in cold MCS cloud cover occur in March-April and are accompanied by a significant increase in wind shear (Fig. 2). This trend has occurred as CAPE has decreased, underlining the importance of wind shear for MCS trends during that season. However, in relative terms, trends in cold MCSs are strongest in OctoberNovember, on average increasing by over $150 \%$ compared to the long-term average MCS cloud cover.

Looking at changes in MCS numbers, trends in FebruaryMay are only significant for the subgroup of cold (rather than all) MCSs, suggesting a dominant contribution from MCS intensification. The frequency of both MCS classes show significant increases later in the year, pointing to a tendency of more frequent events with a smaller increase in intensity. This interpretation is consistent with previous SWA rainfall trend studies: While rainfall extremes increased in both rainy seasons, rainfall totals only show a trend in the second rainy season, albeit with differing significance across studies (Sanogo et al. 2015; Nkrumah et al. 2019; Bichet and Diedhiou 2018).

Since extremes are very likely linked to MCSs, it gives confidence that all these studies identify robust trends in daily extreme rainfall measures. The discrepancy between clear MCS trends and rather weak to nonsignificant trends in total rain might be due to the lower contribution of MCSs. Depending on season, Maranan et al. (2018) attribute 56\%$71 \%$ of SWA total rainfall to MCSs with increasing contribution away from the coast, which however reaches more than $90 \%$ in the Sahel (Mathon et al. 2002). Consequently, the translation of MCS intensification trends into total rainfall trends is likely affected by other types of rain events. Isolated 
convection, warm-rain events, and stratiform rain all contribute, to differing degrees, to total rainfall in SWA (Maranan et al. 2018). Furthermore, trends toward more intense events can occur alongside more prolonged dry periods.

A further limitation in comparing this study to existing work is with respect to local rainfall trends, which can vary considerably across our SWA domain (Nkrumah et al. 2019). Since MCSs are propagating features, detailed spatial trend evaluations would necessitate an analysis on the full diurnal cycle, while we focus on the diurnal convective peak at 1800 UTC only. Hence, our results cannot reflect rainfall trends linked to potential changes in MCS propagation distances or life cycles and might not be representative for regions with nocturnal rainfall peaks. Finally, Hamada et al. (2015) found that under moist tropospheric conditions, most intense rainfall events are on average associated with bottom-heavy radar echoes as opposed to highest vertical extent, illustrating the general limitations in relating convective intensities and rainfall intensities, particularly in moist convective regimes. However, the dominating MCS frequency increase identified here for the moist regime period should have a more robust relationship to rainfall amounts.

Considering preconvective environments, we find that the most intense MCSs (as defined by coldest cloud tops) for either rainy season ultimately occur under similar conditions, in spite of contrasting convective regimes. These conditions are increased low-level humidity, drier midlevels, and stronger lowlevel shear. The principal difference between storm drivers is that during the second rainy season, high shear conditions are rare.

Overall, we find that MCS intensity and maximum rainfall are more than twice as sensitive to changes in wind shear in the prestorm environment as to changes in low-level moisture. This is however related to abundant low-level moisture in SWA on days that favor MCS development and would be less pronounced in a drier environment.

Typical ingredients for conditions that favor deepest, most intense MCSs and severe weather are advection of low-level moist air and steep midlevel lapse rates together with a strongly sheared environment in areas of baroclinicity. This is not only true in West Africa (Hodges and Thorncroft 1997), but has similarly been found in the United States (Coniglio et al. 2010; Schumacher and Johnson 2005), South America (Mulholland et al. 2018; Rasmussen and Houze 2011), Asia (Zheng et al. 2013), and Australia (Laing and Fritsch 2000).

Ultimately we illustrate that both changes in wind shear and atmospheric moisture play a role for MCS trends in SWA. Together with Taylor et al. $(2017,2018)$, this study illustrates the regional transferability of temperature gradient effects on MCSs. Across the world, other MCS hotspots subject to differential warming rates may exhibit similar shear-driven trends. However, over the longer term (e.g., out to 2100), future trends in intense rainfall may be dominated by moisture control (Fitzpatrick et al. 2020). This could happen when increasing atmospheric water vapor outpaces differential warming between regions, or when wind shear thresholds are reached that are counterproductive for convective organization.

On the other hand, new wet/dry transition regions with shear sensitivity might emerge as a consequence of circulation changes. Our ability to explore such possibilities is currently hampered by the limitations of coarse-scale climate models, which cannot explicitly capture convection and hence processes that are linked to MCS dynamics. Such models may therefore be lacking a key feedback linking global warming to more intense MCSs and extreme rainfall. Convectionpermitting models are key for a better understanding of potential future changes in rainfall extremes (Prein et al. 2017; Kendon et al. 2019; Berthou et al. 2019; Vizy and Cook 2018), but their skill in correctly representing the process interactions demonstrated here is still an open question (Fitzpatrick et al. 2020). To improve confidence, process understanding from observations should therefore be used to validate and constrain this new generation of models.

Acknowledgments. The research leading to these results received funding from the U.K.'s Natural Environment Research Council (NERC)/Department for International Development (DFID) Future Climate for Africa program, under the AMMA2050/CLOVER project (grant number NE/M020428/1). We thank John Marsham for very helpful input on instability measures. We acknowledge the providers of key data sets used here (EUMETSAT; NASA). MSG data are available from http://www.eumetsat.int, ECMWF ERA5 reanalysis data are available from the Copernicus Data Store (https://cds.climate. copernicus.eu/) and data from the Global Precipitation Measurement mission are available from https://pmm.nasa.gov/. Special thanks go to the providers of the python packages matplotlib/cartopy, xarray, salem, scipy, metpy, and their dependencies.

\section{REFERENCES}

Alfaro, D. A., 2017: Low-tropospheric shear in the structure of squall lines: Impacts on latent heating under layer-lifting ascent. J. Atmos. Sci., 74, 229-248, https://doi.org/10.1175/JASD-16-0168.1.

_ , and M. Khairoutdinov, 2015: Thermodynamic constraints on the morphology of simulated midlatitude squall lines. J. Atmos. Sci., 72, 3116-3137, https://doi.org/10.1175/JAS-D-14-0295.1.

—_, and M. C. Coniglio, 2018: Discrimination of mature and dissipating severe-wind-producing MCSs with layer-lifting indices. Wea. Forecasting, 33, 3-21, https://doi.org/10.1175/ WAF-D-17-0088.1.

Allan, R. P., C. Liu, M. Zahn, D. A. Lavers, E. Koukouvagias, and A. Bodas-Salcedo, 2014: Physically consistent responses of the global atmospheric hydrological cycle in models and observations. Surv. Geophys., 35, 533-552, https://doi.org/10.1007/ S10712-012-9213-Z.

Allen, M. R., and W. J. Ingram, 2002: Constraints on future changes in climate and the hydrologic cycle. Nature, 419, 224-232, https://doi.org/10.1038/NATURE01092.

Arnaud, Y., M. Desbois, and J. Maizi, 1992: Automatic tracking and characterization of African convective systems on Meteosat pictures. J. Appl. Meteor., 31, 443-453, https://doi.org/10.1175/ 1520-0450(1992)031<3C0443:ATACOA>E2.0.CO;2.

Barnes, G., and K. Sieckman, 1984: The environment of fast- and slowmoving tropical mesoscale convective cloud lines. Mon. Wea. Rev., 112, 1782-1794, https://doi.org/10.1175/1520-0493(1984)112<1782: TEOFAS $>2.0 . \mathrm{CO} ; 2$.

Berthou, S., E. J. Kendon, D. P. Rowell, M. J. Roberts, S. Tucker, and R. A. Stratton, 2019: Larger future intensification of 
rainfall in the West African Sahel in a convection-permitting model. Geophys. Res. Lett., 46, 13 299-13 307, https://doi.org/ 10.1029/2019GL083544.

Bichet, A., and A. Diedhiou, 2018: Less frequent and more intense rainfall along the coast of the Gulf of Guinea in West and Central Africa (1981-2014). Climate Res., 76, 191-201, https:// doi.org/10.3354/CR01537.

CDS, 2017: ERA5: Fifth generation of ECMWF atmospheric reanalyses of the global climate. Copernicus Climate Data Store, accessed 11 May 2020, https://cds.climate.copernicus.eu/ cdsapp\#!/dataset/reanalysis-era5-pressure-levels?tab $=$ form.

Cecil, D. J., S. J. Goodman, D. J. Boccippio, E. J. Zipser, and S. W. Nesbitt, 2005: Three years of TRMM precipitation features. Part I: Radar, radiometric, and lightning characteristics. Mon. Wea. Rev., 133, 543-566, https://doi.org/10.1175/MWR-2876.1.

Coniglio, M. C., J. Y. Hwang, and D. J. Stensrud, 2010: Environmental factors in the upscale growth and longevity of MCSs derived from Rapid Update Cycle analyses. Mon. Wea. Rev., 138, 3514-3539, https://doi.org/10.1175/ 2010MWR3233.1.

Cook, K. H., and E. K. Vizy, 2015: Detection and analysis of an amplified warming of the Sahara Desert. J. Climate, 28, 65606580, https://doi.org/10.1175/JCLI-D-14-00230.1.

Corfidi, S. F., 2003: Cold pools and MCS propagation: Forecasting the motion of downwind-developing MCSs. Wea. Forecasting, 18, 997-1017, https://doi.org/10.1175/ 1520-0434(2003)018<0997:CPAMPF>2.0.CO;2.

Dezfuli, A. K., C. M. Ichoku, G. J. Huffman, K. I. Mohr, J. S. Selker, N. van de Giesen, R. Hochreutener, and F. O. Annor, 2017: Validation of IMERG precipitation in Africa. J. Hydrometeor., 18, 2817-2825, https://doi.org/10.1175/ JHM-D-17-0139.1.

Emori, S., and S. J. Brown, 2005: Dynamic and thermodynamic changes in mean and extreme precipitation under changed climate. Geophys. Res. Lett., 32, L17706, https://doi.org/ 10.1029/2005GL023272.

Fink, A. H., D. G. Vincent, and V. Ermert, 2006: Rainfall types in the West African Sudanian zone during the summer monsoon 2002. Mon. Wea. Rev., 134, 2143-2164, https://doi.org/10.1175/ MWR3182.1.

Fitzpatrick, R. G., and Coauthors, 2020: What drives the intensification of mesoscale convective systems over the West African Sahel under climate change? J. Climate, 33, 31513172, https://doi.org/10.1175/JCLI-D-19-0380.1.

Gelaro, R., and Coauthors, 2017: The Modern-Era Retrospective Analysis for Research and Applications, version 2 (MERRA2). J. Climate, 30, 5419-5454, https://doi.org/10.1175/JCLI-D16-0758.1.

Goyens, C., D. Lauwaet, M. Schröder, M. Demuzere, and N. P. Van Lipzig, 2012: Tracking mesoscale convective systems in the Sahel: Relation between cloud parameters and precipitation. Int. J. Climatol., 32, 1921-1934, https://doi.org/10.1002/ JOC. 2407.

Hamada, A., Y. N. Takayabu, C. Liu, and E. J. Zipser, 2015: Weak linkage between the heaviest rainfall and tallest storms. Nat. Commun., 6, 6213, https://doi.org/10.1038/NCOMMS7213.

Hansen, J., R. Ruedy, M. Sato, and K. Lo, 2010: Global surface temperature change. Rev. Geophys., 48, RG4004, https:// doi.org/10.1029/2010RG000345.

Hardwick Jones, R., S. Westra, and A. Sharma, 2010: Observed relationships between extreme sub-daily precipitation, surface temperature, and relative humidity. Geophys. Res. Lett., 37, L22805, https://doi.org/10.1029/2010GL045081.
Hodges, K. I., and C. D. Thorncroft, 1997: Distribution and statistics of African mesoscale convective weather systems based on the ISCCP Meteosat imagery. Mon. Wea. Rev., 125, 2821-2837, https://doi.org/10.1175/1520-0493(1997)125<2821: DASOAM $>2.0 . \mathrm{CO} ; 2$.

Houze, R. A., 2004: Mesoscale convective systems. Rev. Geophys., 42, RG4003, https://doi.org/10.1029/2004RG000150.

Huffman, G. J., E. F. Stocker, D. T. Bolvin, E. J. Nelkin, and J. Tan, 2019: GPM IMERG Final Precipitation L3 Half Hourly 0.1 degree x 0.1 degree V06. Goddard Earth Sciences Data and Information Services Center (GES DISC), accessed 17 October 2020, https://doi.org/10.5067/GPM/IMERG/3B-HH/06.

IPCC, 2014: Climate Change 2014: Synthesis Report. Cambridge University Press, $151 \mathrm{pp}$.

James, R. P., and P. M. Markowski, 2010: A numerical investigation of the effects of dry air aloft on deep convection. Mon. Wea. Rev., 138, 140-161, https://doi.org/10.1175/ 2009MWR3018.1.

Ji, F., Z. Wu, J. Huang, and E. P. Chassignet, 2014: Evolution of land surface air temperature trend. Nat. Climate Change, $\mathbf{4}$, 462-466, https://doi.org/10.1038/NCLIMATE2223.

Kendon, E. J., R. A. Stratton, S. Tucker, J. H. Marsham, S. Berthou, D. P. Rowell, and C. A. Senior, 2019: Enhanced future changes in wet and dry extremes over Africa at convection-permitting scale. Nat. Commun., 10, 1794, https:// doi.org/10.1038/S41467-019-09776-9.

Klein, C., and C. M. Taylor, 2020: Dry soils can intensify mesoscale convective systems. Proc. Natl. Acad. Sci. USA, 117, 21 13221 137, https://doi.org/10.1073/pnas.2007998117.

_- D. Belušić, and C. M. Taylor, 2018: Wavelet scale analysis of mesoscale convective systems for detecting deep convection from infrared imagery. J. Geophys. Res. Atmos., 123, 30353050, https://doi.org/10.1002/2017JD027432.

Knapp, K. R., and Coauthors, 2011: Globally gridded satellite observations for climate studies. Bull. Amer. Meteor. Soc., 92 , 893-907, https://doi.org/10.1175/2011BAMS3039.1.

Laing, A. G., and J. M. Fritsch, 2000: The large-scale environments of the global populations of mesoscale convective complexes. Mon. Wea. Rev., 128, 2756-2776, https://doi.org/10.1175/15200493(2000)128<2756:TLSEOT>2.0.CO;2.

,-- , and A. J. Negri, 1999: Contribution of mesoscale convective complexes to rainfall in Sahelian Africa: Estimates from geostationary infrared and passive microwave data. J. Appl. Meteor., 38, 957-964, https://doi.org/10.1175/15200450(1999)038<0957:COMCCT>2.0.CO;2.

Lenderink, G., R. Barbero, J. M. Loriaux, and H. J. Fowler, 2017: Super-Clausius-Clapeyron scaling of extreme hourly convective precipitation and its relation to large-scale atmospheric conditions. J. Climate, 30, 6037-6052, https://doi.org/10.1175/ JCLI-D-16-0808.1.

Liu, S. C., C. Fu, C. J. Shiu, J. P. Chen, and F. Wu, 2009: Temperature dependence of global precipitation extremes. Geophys. Res. Lett., 36, L17702, https://doi.org/10.1029/ 2009 GL040218.

Lorenz, C., and H. Kunstmann, 2012: The hydrological cycle in three state-of-the-art reanalyses: Intercomparison and performance analysis. J. Hydrometeor., 13, 1397-1420, https:// doi.org/10.1175/JHM-D-11-088.1.

Maidment, R. I., R. P. Allan, and E. Black, 2015: Recent observed and simulated changes in precipitation over Africa. Geophys. Res. Lett., 42, 8155-8164, https://doi.org/10.1002/2015GL065765.

Maranan, M., A. H. Fink, and P. Knippertz, 2018: Rainfall types over southern West Africa: Objective identification, climatology 
and synoptic environment. Quart. J. Roy. Meteor. Soc., 144, 1628-1648, https://doi.org/10.1002/QJ.3345.

,,,--- L. K. Amekudzi, W. A. Atiah, and M. Stengel, 2020: A process-based validation of GPM IMERG and its sources using a mesoscale rain gauge network in the West African forest zone. J. Hydrometeor., 21, 729-749, https:// doi.org/10.1175/JHM-D-19-0257.1.

Mathon, V., H. Laurent, and T. Lebel, 2002: Mesoscale convective system rainfall in the Sahel. J. Appl. Meteor., 41, 1081-1092, https:// doi.org/10.1175/1520-0450(2002)041<1081:MCSRIT>2.0.CO;2.

Mohr, K. I., and E. J. Zipser, 1996: Mesoscale convective systems defined by their $85-\mathrm{GHz}$ ice scattering signature: Size and intensity comparison over tropical oceans and continents. Mon. Wea. Rev., 124, 2417-2437, https://doi.org/10.1175/ 1520-0493(1996)124<2417:MCSDBT>2.0.CO;2.

—, and C. D. Thorncroft, 2006: Intense convective systems in West Africa and their relationship to the African easterly jet. Quart. J. Roy. Meteor. Soc., 132, 163-176, https://doi.org/ 10.1256/QJ.05.55.

Moseley, C., C. Hohenegger, P. Berg, and J. O. Haerter, 2016: Intensification of convective extremes driven by cloud-cloud interaction. Nat. Geosci., 9, 748-752, https://doi.org/10.1038/ ngeo2789, 1510.03831.

Mulholland, J. P., S. W. Nesbitt, R. J. Trapp, K. L. Rasmussen, and P. V. Salio, 2018: Convective storm life cycle and environments near the Sierras de Córdoba, Argentina. Mon. Wea. Rev., 146, 2541-2557, https://doi.org/10.1175/MWR-D18-0081.1.

Nesbitt, S. W., R. Cifelli, and S. A. Rutledge, 2006: Storm morphology and rainfall characteristics of TRMM precipitation features. Mon. Wea. Rev., 134, 2702-2721, https://doi.org/ 10.1175/MWR3200.1.

Nicholls, S. D., and K. I. Mohr, 2010: An analysis of the environments of intense convective systems in West Africa in 2003. Mon. Wea. Rev., 138, 3721-3739, https://doi.org/ 10.1175/2010MWR3321.1.

Nicholson, S. E., 2018: Climate of the Sahel and West Africa. Oxford Research Encyclopedias, Vol. 510, 40 pp., https://doi.org/ 10.1093/acrefore/9780190228620.013.510.

Nie, J., A. H. Sobel, D. A. Shaevitz, and S. Wang, 2018: Dynamic amplification of extreme precipitation sensitivity. Proc. Natl. Acad. Sci. USA, 115, 9467-9472, https://doi.org/10.1073/ PNAS.1800357115.

Nkrumah, F., T. Vischel, G. Panthou, N. A. B. Klutse, D. C. Adukpo, and A. Diedhiou, 2019: Recent trends in the daily rainfall regime in southern West Africa. Atmosphere, 10 (12), 1-15, https://doi.org/10.3390/ATMOS10120741.

Omotosho, J. B., 1985: The separate contributions of line squalls, thunderstorms and the monsoon to the total rainfall in Nigeria. J. Climatol., 5, 543-552, https://doi.org/10.1002/ joc. 3370050507.

- 1990: Onset of thunderstorms and precipitation over northern Nigeria. Int. J. Climatol., 10, 849-860, https://doi.org/ 10.1002/JOC.3370100807.

Pall, P., M. R. Allen, and D. A. Stone, 2007: Testing the ClausiusClapeyron constraint on changes in extreme precipitation under $\mathrm{CO}_{2}$ warming. Climate Dyn., 28, 351-363, https:// doi.org/10.1007/S00382-006-0180-2.

Panthou, G., T. Vischel, and T. Lebel, 2014: Recent trends in the regime of extreme rainfall in the central Sahel. Int. J. Climatol., 34, 3998-4006, https://doi.org/10.1002/JOC.3984.

Parker, D. J., C. D. Thorncroft, R. R. Burton, and A. DiongueNiang, 2005: Analysis of the African easterly jet, using aircraft observations from the JET2000 experiment. Quart. J. Roy. Meteor. Soc., 131, 1461-1482, https://doi.org/10.1256/QJ.03.189.

Peters, J. M., C. J. Nowotarski, and H. Morrison, 2019: The role of vertical wind shear in modulating maximum supercell updraft velocities. J. Atmos. Sci., 76, 3169-3189, https://doi.org/ 10.1175/JAS-D-19-0096.1.

Prein, A. F., C. Liu, K. Ikeda, S. B. Trier, R. M. Rasmussen, G. J. Holland, and M. P. Clark, 2017: Increased rainfall volume from future convective storms in the US. Nat. Climate Change, 7, 880-884, https://doi.org/10.1038/S41558-0170007-7.

Rasmussen, K. L., and R. A. Houze, 2011: Orogenic convection in subtropical South America as seen by the TRMM satellite. Mon. Wea. Rev., 139, 2399-2420, https://doi.org/10.1175/ MWR-D-10-05006.1.

Roca, R., J. P. Lafore, C. Piriou, and J. L. Redelsperger, 2005: Extratropical dry-air intrusions into the West African monsoon midtroposphere: An important factor for the convective activity over the Sahel. J. Atmos. Sci., 62, 390-407, https:// doi.org/10.1175/JAS-3366.1.

Sanogo, S., A. H. Fink, J. A. Omotosho, A. Ba, R. Redl, and V. Ermert, 2015: Spatio-temporal characteristics of the recent rainfall recovery in West Africa. Int. J. Climatol., 35, 45894605, https://doi.org/10.1002/JOC.4309.

Schmetz, J., P. Pili, S. Tjemkes, D. Just, J. Kerkmann, S. Rota, and A. Ratier, 2002: An introduction to Meteosat second generation (MSG). Bull. Amer. Meteor. Soc., 83, 977-992, https:// doi.org/10.1175/1520-0477(2002)083<0977:AITMSG>2.3. $\mathrm{CO} ; 2$.

Schumacher, R. S., and R. H. Johnson, 2005: Organization and environmental properties of extreme-rain-producing mesoscale convective systems. Mon. Wea. Rev., 133, 961-976, https://doi.org/10.1175/MWR2899.1.

Singleton, A., and R. Toumi, 2013: Super-Clausius-Clapeyron scaling of rainfall in a model squall line. Quart. J. Roy. Meteor. Soc., 139, 334-339, https://doi.org/10.1002/QJ.1919.

Smith, R. K., and M. T. Montgomery, 2012: Observations of the convective environment in developing and non-developing tropical disturbances. Quart. J. Roy. Meteor. Soc., 138, 17211739, https://doi.org/10.1002/QJ.1910.

Taylor, C. M., and Coauthors, 2017: Frequency of extreme Sahelian storms tripled since 1982 in satellite observations. Nature, 544, 475-478, https://doi.org/10.1038/NATURE 22069.

— A. H. Fink, C. Klein, D. J. Parker, F. Guichard, P. P. Harris, and K. R. Knapp, 2018: Earlier seasonal onset of intense mesoscale convective systems in the Congo basin since 1999. Geophys. Res. Lett., 45, 13 458-13 467, https://doi.org/10.1029/ 2018GL080516.

Thorncroft, C. D., H. Nguyen, C. Zhang, and P. Peyrille, 2011: Annual cycle of the West African monsoon: Regional circulations and associated water vapour transport. Quart. J. Roy. Meteor. Soc., 137, 129-147, https://doi.org/10.1002/ QJ.728.

Toledo Machado, L. A., M. Desbois, and J. P. Duvel, 1992: Structural characteristics of deep convective systems over tropical Africa and the Atlantic Ocean. Mon. Wea. Rev., 120, 392-406, https://doi.org/10.1175/1520-0493(1992)120<0392: SCODCS $>2.0 . \mathrm{CO} ; 2$.

Trenberth, K. E., A. Dai, R. M. Rasmussen, and D. B. Parsons, 2003: The changing character of precipitation. Bull. Amer. Meteor. Soc., 84, 1205-1217, https://doi.org/10.1175/BAMS84-9-1205. 
Vizy, E. K., and K. H. Cook, 2017: Seasonality of the observed amplified Sahara warming trend and implications for Sahel rainfall. J. Climate, 30, 3073-3094, https://doi.org/10.1175/ JCLI-D-16-0687.1.

_ and - 2018: Mesoscale convective systems and nocturnal rainfall over the West African Sahel: Role of the inter-tropical front. Climate Dyn., 50, 587-614, https://doi.org/10.1007/ S00382-017-3628-7.

Wei, N., L. Zhou, Y. Dai, G. Xia, and W. Hua, 2017: Observational evidence for desert amplification using multiple satellite datasets. Sci. Rep., 7, 2043, https://doi.org/10.1038/S41598-017-02064-W.
Westra, S., and Coauthors, 2014: Future changes to the intensity and frequency of short-duration extreme rainfall. Rev. Geophys., 52, 522-555, https://doi.org/10.1002/2014RG000464.

Zheng, L., J. Sun, X. Zhang, and C. Liu, 2013: Organizational modes of mesoscale convective systems over central East China. Wea. Forecasting, 28, 1081-1098, https://doi.org/ 10.1175/WAF-D-12-00088.1.

Zipser, E. J., D. J. Cecil, C. Liu, S. W. Nesbitt, and D. P. Yorty, 2006: Where are the most intense thunderstorms on Earth? Bull. Amer. Meteor. Soc., 87, 1057-1071, https://doi.org/ 10.1175/BAMS-87-8-1057. 